\title{
Bedingungen sozialistischer Gewerkschaftsarbeit
}

\author{
(,"Thesen zur Gewerkschaft", veränderte und erweiterte Fassung des Referats für \\ die Tagung des Sozialistischen Büros" zur Gewerkschaftsfrage in Frankfurt, \\ Februar 1974)
}

Redaktionskollektiv Gewerkschaften*

Die nachstehenden Thesen wurden vom Redaktionskollektiv Gewerkschaften für die Arbeitstagung des Sozialistischen Büros im Februar 1974 zu Fragen der Gewerkschaftsarbeit verfaßt. Wir haben darin versucht, wesentliche Ergebnisse unserer bisherigen Analysen zusammenzufassen und sie auf zentrale Probleme in den aktuellen A useinandersetzungen zwischen Lohnarbeit und Kapital $z u$ beziehen. Dabei setzen wir im folgenden insbesonders den in den Thesen zur Gewerkschaftsanalyse (1) erarbeiteten allgemeinen Zusammenhang von Kapitalbewegung und gewerkschaftlichem Lohnkampf voraus. Darüberhinaus war es aber gerade deshalb, weil wir aktuelle Probleme der Arbeiterbewegung aufarbeiten wollten, notwendig, die begriffliche Ebene im Hinblick auf die Konkurrenz weiter auszudifferenzieren, da gerade in den letzten Auseinandersetzungen (sei es in den spontanen, sei es in den geverkschaftlich angeleiteten Kämpfen) die Konkurrenz zwischen den Arbeitern (einzelner Betriebe, verschiedener Qualifikation, verschiedener Nationalität) ein entscheidendes Hemmnis in der Entwicklung der Arbeiterbewegung darstellte. Wir halten es daher auch für einen schwerwiegenden Fehler in der Beurteilung der letzten Auseinandersetzungen zwischen Kapital und Arbeit, wenn aus einer gegenüber früheren Kämpfen quantitativ ausgeweiteten und inhaltlich teils veränderten Bewegung bereits auf eine (sich quasi linear entwickelnde) wachsende Breite, Tiefe und Reife der Bewegung geschlossen wird (2) und so die Ursachen der stattgefundenen Niederlagen nicht mehr in den Blick geraten, oder aber wenn im Gewerkschaftsapparat bzw. in der Gewerkschaftsführung kurzschlüssig der Sündenbock für das Scheitern der Kämpfe gefunden wïrd (3).

Zuin anderen wurden die Probleme der Arbeiter in viel stärkerem Maße als zuvor in den letzten Jahren als gesamtgesellschaftliche erfahren, sei es im D ruck auf den Reallohn (vermittelt über die Inflation), sei es über eine sich herausbildende industrielle Reservearmee. Auf die

* hier: Hajo Funke, Siegfried Heimann, Jürgen Hoffmann, Dieter Läpple, Thomas Mitscherlich, Christel Neusüß und Bodo Zeuner

1) vgl. dazu Thesen zur Gewerkschaftsanalyse, in Probleme des Klassenkampfs Nr. 2/1972, S. 87 , in denen wir die gegensätzliche Bestimm theit der Gewerkschaften, als Organisationen der Lohnarbeiter im Lohnsystem integriert zu sein und als Organisationen des Gegensatzes der Lohnarbeit gegen das Kapital zugleich Potenzen des Klassenkampfs freisetzen zu müssen, allgemein entwickelt haben.

2) Als Beispiel kann hier der Aufsatz von Steinhaus (Kurt Steinhaus, Zur Entwicklung des Kampfes und des Bewußtseins der Arbeiterklasse in der BRD 1973, in: Marxistische Blätter, Nr. 1/1974) herangezogen werden, in dem die Zersplitterung der Aktionen, die erfahrenen Niederlagen nicht reflektiert werden; die zeitliche Zersplitterung der Kämpfe und die Neutralisierung der kampfstarken Betriebe in der Stahlindustrie werden eher positiv gewertet. Damit soll nicht unterschlagen werden, daß der Artikel vorwärtstreibende Momente anschaulich macht.

3) so in der Broschüre des Redaktionskollektivs ,express“, Spontane Streiks 1973, Krise der Gewerkschaftspolitik F. a. M. 1974; die Verfasser gelangen denn auch in ihren politischen Schlußfolgerungen nicht darüberhinaus, ihre alten Rezepte linker Gewerkschaftsarbeit erneut den sozialistischen Gewerkschaftlern anzuempfehlen: betriebsnahe Tarifpolitik, betriebsnahe Bildungsarbeit, limke Vertrauensleutearbeit und die Forderung nach der Transformierung der Gewerkschaften in autonome Klassenorganisationen! 
veränderten Bedingungen im Akkumulationsprozeß, die diese Probleme der Reproduktion der Arbeitskraft zum Resultat hatten, können wir hier nicht näher eingehen, verweisen aber auf den im selben Heft abgedruckten Artikel zur Akkumulation des westdeutschen Kapitals (der in PROKLA 14/15 fortgesetzt werden wird), der unseren Thesen mit zugrundelag.

Dieser Bezug auf die Klassenbewegung insgesamt und auf die historisch entwickelten Probleme der A theiterklasse Anfang der siebziger Jahre sollte dazu dienen, Elemente einer sozialistischen Gewerkschaftspolitik herauszuarbeiten, die einerseits von der Marxschen Analyse der bürgerlichen Geselischaft ausgeht und andererseits an den konkreten Problemen der Arbeiter und der Gewerkschaftsbewegung anknüpft. Aus dieser Intention heraus mußten wir im zweiten Teil unserer Thesen uns mit vorhandenen Vorstellungen einer linken Gewerkschaftspolitik auseinandersetzen, wie sie insbesonders von Gruppen vertreten werden, die mit dem Sozialistischen Büro zusammenarbeiten (z. B. des Redaktionskollektivs, ,express ${ }^{6}$ ), die aber auch - im Gefolge einer traditionellen linken Gewerkschaftsarbeit in den fünfziger und sechziger Jahren - von vielen linken Gewerkschaftskadern verfolgt werden. So sind Vorsteilungen von einer linken ,betriebsnaher Tarifpolitik ${ }^{6}$, linken, Vertrauensleutearbeit', ,betriebsnaher Bildungs ${ }^{*}$ arbeit ${ }^{6}$ und von der, Transformation der Gewerkschaften in autonome Gewerkschaftsorganisationen" nicht hirureichend auf die Klassenbewegung bezogen und teils modellhaft dieser aufgepfropft, teils historisch überkommen und vermögen daher die Arbeit von Sozialisten in den Gewerkschaften nur unvollkommen auszudrïcken, wenn sie nicht gar zum Hemmnis der Klassenbewegung werden. Andererseits sind solche Konzeptionen sowohl historisches Resultat einer spezifischen Periode der Kapital- und Gewerkschaftsentwicklung in der BRD wie auch der im Kapitalverhältnis gesetzten Widersprüche und der Mystifikation des Ausbeutungsverhältnisses. Unsere Kritik wird sich daher auch nicht abstrakt auf ein besseres Modell gewerkschaftliche: Politik beziehen, sondern soll - exemplarisch an der betriebsnahen Tarifpolitik - herausarbeiten, welche beschränkten Anknüpfungspunkte diese Modelle gewerkschaftlicher Politik aufweisen und welche - den Intentionen det Verfasser entgegengesetzten - Bewegungen sie ausdrücken bzw. befördern können.

Schon aus diesen kurzen Ausführungen dürfte deutlich geworden sein, daß die hier vorgelegten Thesen des Redaktionskollektivs nicht die allgemeine theoretische Ableitung der Gewerkschaftsfrage darstellen, die dann durch Konzeptionen, wie sie etwa von der Redaktion des ,express" vertreten werden, beliebig prakrisch zu wenden resp. auszufüllen sind, sondern dał es sich hierbei um prinzipielle politische Fragen handelt, um eine politische Kontroverse, die auch nicht von den methodischen Voraussetzungen der Diskutanten getrennt werden darf.

\section{Einleitung}

Die Frage, wie sich Sozialisten auf die Gewerkschaft beziehen sollen, muß von der grundsätzlicheren ausgehen, wie sie sich auf die Klassenbewegung selbst beziehen sollen.

Ausgangspunkte müssen also sein:

- die Bestimmung des Widerspruchs zwischen Lohnarbeit und Kapital auf der Basis der Marxschen Theorie;

- die konk reten historischen Erscheinungsormen, der Entwicklungsgrad dieses Widerspruchs und die zu erwartende Entwicklungsrichtung;

- die Notwendigkeit der Organisation der Arbeiter gegen das Kapital in Gewerkschaften;

- der Doppelcharakter der Gewerkschaften selbst als Interessenvertretung innerhalb der bürgerlichen Gesellschaft und als Organisation, die den offenen Kassenkampf mit dem Kapital fuhrt; der historische Zustand der gewerkschaftlichen Organisation und die Frage, 
wie weit ihre Aufgaben wahrgenommen werden.

Diese Fragen können nicht allein durch Verallgemeinerung der unmittelbaren Erfak rung beantwortet werden. So entscheidend wichtig es ist, in jeder Einschätzung der Lage der Klassenkämpfe, der Entwicklung der Organisationen der Arbeiterklasse, der Operationen des Klassengegners, der Machtverhältnisse der Klassen, des inneren Zustands der Arbeiterklasse den wirklichen, ïber die historische Erfahrung vermittelten Gang der Entwicklung genauestens nachzuvollziehen, so ist eine Analyse der Verhältnisse, welche den Zersetzungsprozeß der bürgerlichen Gesellschaft nachzuzeichnen versucht, um in ihn vorwärtstreibend einzugreifen und Alternativen einer neuen Gesellschaft zu entwickeln, doch nur auf der Gnundlage des wissenschaftlichen Sozialismus möglich. Die in der Marxschen Theorie enthüllte Anatomie der bürgerlichen Gesellschaft muß die theoretische Grundlage sein, mit welcher der historische Entwicklungsgang auf seine inneren Bewegungsgesetze und Entwicklungsrichtungen hin aufgeschlüsselt wird. Ein Verständnis der Klassenbewegung und ihres historischen Ziels ist dabei die Grundlage, auf welcher eine dauerhaft richtige politische Praxis entwickelt werden muß. Wie die Erfahrungen (gerade von Gruppen, die im Zusammenhang mit dem Sozialistischen Büro stehen) zeigen, genügt eine Summierung der in den praktischen Auseinandersetzungen mit der herrschenden Gesellschaftsordnung gemachten Erfahrungen noch nicht, um sich der eigenen Zielsetzung und der Schritte, welche hin zum Ziel zu machen sind, zu versichern. Andererseits hilft die pure Rezeption der Marxschen Theorie allein ebensowenig weiter.

Es wäre falsch, davon auszugehen, die praktische Auseinandersetzung mit dem Klassengegner sei erst dann aufzunehmen, wenn die Analyse der Klassenverhältnisse fertig auf dem Tisch liege.

Vielmehr muß davon ausgegangen werden, daß die Analyse selbst aus dem Zusammenhang der praktischen Kämpfe entwickelt werden muß.

- Es wäre falsch, die gegenwärtig existierende Unsicherheit hinsichtlich der politischen Linie, welcher die praktischen Kämpfe zu folgen hätten, voluntaristisch durch die Übernahme historischer Interpretationen des Klassenkampfes zu überspringen, wie dies gegenwärtig allenthalben in den verschiedenen, aus der Studentenrevolte hervorgegangenen kommunistischen Zirkeln getan wird. Dies fuihrt nur zum Abschneiden der Erfahrung auf der einen, zur Restriktion der sozialistischen Theorie auf der anderen Seite. Dabei sind derartig verkürzte Interpretationsmuster; die selbst noch Resultat einer sich erst wieder neu entfaltenden linken Bewegung sind, aus dem Grund zu kritisieren, weil die in ihnen vollzogenen Abstraktionen vom wirklichen historischen Gang dazu führen, daß der Wirklichkeit ein falsches Bild von ihr aufgepreßt wird, was mit Notwendigkeit zu Fehlern führen muß, die der Entwicklung des Klassenkampfs entgegenstehen können. Die Ablehnung von Dogmatisierungen folgt also nicht etwa einem bürgerlichen Ideal von schein bar vorurteilsfreier Wissenschaft, sondern nur den Notwendigkeiten der Klassenauseinandersetzung selbst.

- Jeder Versuch, im Prozeß der Auseinandersetzung innerhalb der Linken und mit dem Klassengegner politische Vorstellungen des praktischen Handelns zu 
entwickeln, muß davon ausgehen, daß die Erklärung der wirklichen Verhältnisse, auf deren Grundlage Handlungsperspektiven entwickelt werden, in einer Weise mit den wirklichen Erfahrungen und den erfahrenen Aufgaben verknüpft sein muß, daß sie von den Handelnden selbst kontrolliert werden kann. Darin ist aber andererseits impliziert, daß die theore tische Erklärung der wirklichen Verhältnisse nicht als fertiges Produkt von den Theoretikern geliefert wird in der Form einer unmittelbar praktischen Handlungsanweisung.

\section{Warum organisieren sich die Abeiter in den Gewerkschafter?}

\section{1}

Die gewerkschaftliche Organisation der Arbeiter ist das notwendige Resultat der Tatsache, daß sich Lohnarbeit und Kapital als ausgebeute te und ausbeutende Klasse gegenüberstehen. Diese zunächst banal erscheinende Aussage ist wichtig. Denn sie schließt ein, daß jede Analyse des historischen Zustands von Gewerkschaftsorganisationen auszugehen hat von der Analyse des Entwicklungsstands des Klassengegensatzes sowie seiner Entwicklungsrichtung. Erst auf dieser Grundlage kann die Frage gestellt werden, in welcher Weise der konkrete organisatorische und politische $\mathrm{Zu}$ stand der Gewerkschaft die Entwicklung der Klassenkämpfe fördert, und in wieweit er ihn hemmt. Von da aus müssen politische Positionen zur Gewerkschaftsfrage, welche z. B. die organisatorische Verselbständigung des Gewerkschaftsapparates gegenüber der Gewerkschaftsbasis, einen historisch verfestigten Reformismus oder gar den bloßen ,Verrat der Interessen der Arbeiterklasse durch die Gewerkschaftsbürokratie" zum Ausgangspunkt ihrer Strategie gegenüber und innerhalb der Gewerkschaftsorganisationen machen, als falsch zurückgewiesen werden.

\section{2}

Daß die Arbeiter sich in Gewerkschaften zusammenschließen, resultiert daraus, daß sie als individuelle Warenverkäufer nicht mit dem Kapital konkurrieren könne (9)

4) Um Mißverständnisse zu vermeiden, hier das Zitat bei Marx, auf das wir uns beziehen: „Der Arbeitslohn ist, wie wir gesehn haben, der Preis einer bestimmten Ware, der Arbeitskraft. Der Arbeitslohn wird also durch dieselben Gesetze bestimmt, die den Preis jeder andern Ware bestimmen. Es fragt sich also, wie wird der Preis einer Ware bestimmt? Wodurch wird der Preis einer Ware bestimmt? Durch die Konkurrenz zwischen Käufern und Verkäufern, durch das Verhältnis der Nachfrage zur Zufuhr, des Begehrs zum Angebot. Die Konkurrenz, wodurch der Preis einer Ware bestimmt wird, ist dreiseitig. Dieselbe Ware wird von verschiedenen Verkäufern angeboten ... Es findet also eine Konkurrenz unter den Verkäufern statt, die den Preis der von ihnen angebotenen Waren herabdrückt. Es findet aber auch eine Konkurrenz unter den Käufern statt, die ihrerseits den Preis der angebotnen Waren steigen macht. Es findet endlich eine Konkurrenz unter den Räufern und Verkäufern statt; die einen wollen möglichst wohlfeil kaufen, die 
„Die Ware Arbeitskraft hat große Nachteile vor anderen Waren. Für den Kapitalisten handelt es sich bei der Konkurrenz mit den Arbeitern nur um den Frofit, bei den Arbeitern um die Existenz ${ }^{66}$ (Marx). Der Kapitalist ist Besitzer der Produktionsmittel, ihm gehört das Produkt, das der Arbeiter produziert. In seiner Akkumulation produziert das Kapital mit Notwendigkeit eine industrielle Reservearmee, deren Druck auf die Beschäftigten in unterschiedlichem Maße während der Phasen des Akkumulationsprozesses wirkt. Abgesehen von der Stellung bestimmter qualifizierter Arbeiterschichten in Phasen außergewöhnlicher Akkumulation sind die Arbeiter als Anbieter der Ware Arbeitskraft immer im Nachteil gegenüber den Kapitalisten als den Nachfragern. Das Anbieten der Arbeitskraft zwingt die Arbeiter als einzelne Warenverkäufer in eine Konkurrenz zueinander, über welche dem Kapital die Be. grenzung des Arbeitslohns gelingt. Der Kapitalist kann Arbeitskraft durch Maschinerie ersetzen und so die Maschinerie als Konkurrenzmittel gegen den Arbeiter einsetzen. Mit dem Eintritt in die Produktionssphäre unterwirft sich der Arbeiter vollends dem Kapital. Denn dem Kapitalisten als Käufer der Ware Arbeitskraft gehört ihr Gebrauch während des Produktionsprozesses. Damit ist ihm die Möglichkeit gegeben, die Arbeitskraft nach den von ihm gesetzten Bedingungen auszurauben.

Insgesamt stellt das Kapital konzentrierte gesellschaftliche Macht dar. Die einzige Macht der Arbeiter dagegen ist ihre Zahl. Um überhaupt als Warenverkäufer mit dem Kapital konkurrieren zu können, müssen die Arbeiter sich zusammenschlieBen, d. h. die Konkurrenz unter sich aufzuheben suchen.

Durch den Zwang, sich als Individuum zu reproduzieren, sind die Arbeiter zueinander in Konkurrenz gesetzt. Diese Konkurrenz der Arbeiter untereinander findet auf folgenden Ebenen statt:

Einmal kann sich der eine Arbeiter billiger verkaufen als der andere, womit er an der allgemeinen Herabsetzung des Lebensniveaus mitwirkt.

- Zum anderen kann er den Versuch machen, durch Mehrleistung im Produktionsprozeß mit den anderen Arbeitern zu konkurrieren.

Beidemal führt hier die Konkurrenz der Arbeiter als Verkäufer zur Verschlechterung ihrer Situation.

- Zum dritten können einzelne Arbeiter dadurch mit dem Kapital zu konkurrieren suchen, daß sie ihrer Arbeitskraft eine besondere Qualifikation verleihen und danit den Druck der Konkurrenz der anderen Arbeiter auf sich zu vermindern suchen. Aber da das Kapital im Prozeß der Veränderung der technischen und organisatorischen Grundlagen seiner Produktion wechselnde Quali-

andern wollen möglichst teuer verkaufen. Das Resultat dieser Konkurrenz zwischen Käufern und Verkäufern wird davon abhängen, wie sich die beiden früher angegebenen Seiten der Konkurrenz verhalten, d. h. ob die Konkurrenz in dem Heer der Käufer oder die Konkurrenz in dem Heer der Verkäufer stärker ist. Die Industrie führt zwei Heeresmassen gegeneinander ins Feld, wovon eine jede in ihren eigenen Reihen zwischen ihren eigenen Truppen wieder eine Schlacht liefert. Die Heeresmasse, unter deren Truppen die geringste Prügelei stattfindet, trägt den Sieg über die entgegenstehende davon." (Karl Marx, Lohnarbeit und Kapital, MEW Bd. 6, Berlin (DDR) 1968, S. 402) Wir beziehen uns hier also auf die Konkurrenz, wie sie das gewöhnliche Bewußtsein der Produktionsagenten (Arbeiter, Kapitalist) beherrscht. 
fikationen nachfragt, ist auch die besondere Qualifikation eines Arbeikers kein auf die Dauer gesichertes Konkurrenzmittel. Dies gilt insbesondere in $\mathrm{K}_{\mathrm{K}} \mathrm{risen}$ phasen der kapitalistischen Entwicklung.

In jedem Fall kommt die Konkurrenz der Arbeiter untereinander dem Kaptal zugute.

Der gewerkschaftliche Zusammenschluß hat für die Arbeiter die Funktion, die Formen ihrer gegenseitigen Konkurrenz einzuschränken und das Kapital unter Druck setzen zu können durch Verweigerung der Arbeitsleistung. Sie ist Tonasssetzung dafür, daß die Arbeiter ihre Arbeitskraft überhapt au ihrem Were werkoujen bönnen, sich alsgesellschaftliche Individuen reproduzieren konnen und nicht auf das Existenzminimum herabgedrükt werden. Eine endgültige Aufhebung der Konkr. renz ist durch die Gewerkschaftsorganisation demgegenuber nicht möghich.

\section{3}

Bilden die Arbeiter nun gewerkschaftliche Zusammenschiusse, um üuerhaupt gegenüber dem Kapital konkurrieren zu können, so heißt das noch nicht notwendig, dar sie auch ihren antagonistischen Gegensatz zum Kapital als gesellschartliche Klasse begreifen. Die gewerkschaftliche Organisation hebt die Schwäche des einzelnen A.rbeiters als Warenverkäufer gegenüber dem $\mathbb{K}$ apital aur̂. Sie stell erst die Bedingungen her, unter der die Arbeiter als Warenbesitzer (Arbeitskraft) und Warenverkäfer ein Äquivalent (,gerechter Lohn") für den Verkauf ihrer Arbeisk raft eizielen können. Auch das Verhältnis zwischen Lohnarbeit und Kapital erscheint in histor. schen Phasen, wo die Arbeiterklasse noch keine gewerkschaftliche Organisation gebildet hat bzw. diese politisch unterdrickt wird, als reines Herrschaftsverhältris. Die gewerkschaftliche Organisation ist in der Regel Voraussetzung dafifi, daß sich der Schein des Äquivalententausches, der Schein, Arbeit und Kapital träten sich als gleichberechtigte Tauschpartner gegenüber, überhaupt erst ausoilden kann. Der Lohn als ,gerechter Arbeitspreis" wird in der Regel erst unter dieser Bedingung historisch wirksam. (Ausnahme von der Regel dort, wo aufgrund besonderer historischer Bedingungen - z. B. USA - der Mechanismus der Reservearmee in bestimmten Phasen der Entwicklung nicht funktioniert.)

Wird also den Arbeitern die Notwendigkeit der gewerkschaftlichen Organisa. tion aufgezwungen, so begreifen sie damit nicht unmittelbar, das das historische Ziel ihrer Organisation nicht mit der Konkurrenz mit dem Kapital abgeschlossen ist und daß sie sich als gesellschaftliche Klasse zır Umwälzung der kapitalistischen Gesellschaft organisieren müssen. Die Erfolge, welche die Gewerkschaften als Ver" einigungen der Arbeiter insbesondere in Phasen prosperierender Kapitalakkumilation in bezug auf die Verbesserung der Lebens- und Arbeitsbedingungen durchsetzen können, fördern bei den Arbeitern durchaus die Vorstellung, daß ihr gewerkschaftlicher Zusammenschluß, aber auch ihre Vertretung im bürgerlichen Parlament hinreiche, um innerhalb der bestehenden gesellschaftlichen Verhältnisse ihre Lage dauerhaft gegenüber dem Kapital sichern und verbessern zu können. Diese lllusion wird bestärkt durch die Erscheinung des Lohns als Preis der Arbeit, in der das 
Ausbeutungsverhältnis, die Aneignung unbezahlter Arbeit durch das Kapika, verdeckt ist. Die Arbeit selbst erschein tann neben Kapital und Boden als gleichrangiger, naturlicher Produkionsfaktor. Die gesellschaftichen Bedingungen erscheinen als natüliche Bedingungen (Kapitel = Produktionsmittel, Lohnarbeit = Arbeit wber haupt). Die Gewerkschaft erscheint als Mittel, die Stellung des Arbeiters als, gleichrangigem Produktionsagenten" neben dem ,Produktionsagenten Kapital und Boden" inmerhalb der Gesellschaft durchzusetzen. (Vgl. etwa die gewerkschaftiche Forderung nach der Gleichberechtigung von Kapital und Arbeit in der Mibestimmungskonzeption.

Die gewerkschafliche Aktion richiet sich dann auf dia proportioneh gechte Vertellung des vor den ,Produktionsfaktoren Arbeit, Boden und Kapitals produzierten Produkts auf die Besitzer dieser unterschiedhchen Produktionsfaktoren. (Vg1. Orienticrung von Iohnpolitik u. a. an Produktivitätszuwächsen.) Die Arbeit als Produktionsfaktor erscheint als Dinkommensquelle, als spezifisches Eigenturb des Arbeiters, die - vermittelt uber die Gewerkschaft - an das Kapital verkauft wird. Gerechte Einkonmensverteilung zwischen den Produktionsfakiopen erschein als Ziel der gewerkschaftichen Vereinigurg. Daß sich im historischen Rrozeß der Akinumation der Reichum des Kapitals ubermäBig vemehrt gegenüber dem Anteil der Axbeiterklasse am gewachsenen Reichtum, wird allerdings erst dann wirklich zum Problen, wem das Kapital seine Angriffe auf die Lebenslage der Arbeiter beginnt. Solange das nicht der Fall ist, erscheint diese ungleiche Verteilung des wachsenden gesellschaftlichen Reichtums zwischen Lohnarbeit und Kapital als durchaus zufäliger ind veränderbarer Umstand. (Vgl. Strategien wie: Lohnpolitik der Umverteilung, Eigenturnsbildung in Arbeitnehmerhand.)

\section{4}

Darin ist aber eingeschlossen, daß die Arbeiter in Phasen, wo die Akkumulationsfähigkeit des Kapitals abnimmt, die Verschlechterung bzw. auch die Begrerizung der Verbesserung threr Lebensbedingungen notwendig zunächst als Resultat von Mängeln und Fehlern inrer gewerkschaftlichen Organisien oder auch als falsche Politik, ihrer politischen Vertretung (z. B. Sozialdemokratie) begreifen werden. Denn gehen sie davon aus, das ih Zusammenschluß die Bedingung der dauerhaften Verbessenung ihrer Exisienz gegenuber dem Kapital ist, so muß eben eine Verschlechterung zunächs auch auf die Fomen des Zusammenschlusses zurückgeführt werden. So ist der Wiederbeginn der Klassenkämpfe in Westeuropa seit der Mitte der 60er Jahre allenthalben gekennzeichnet durch außerordentlich harte Auseinandersetzungen zwischen kampfbereicen Arbeitern und traditioneller Gewerkschaftsorganisation. Hier entwickeln sich im Kampf gegen das Kapital erst auch die Widersprüche in der eigenen Organisation, die dann in ihrer Erscheinung als Widersprüche zwischen Gewerkschaftsbasis und Apparat bzw. Buirokratie nur unzureichend erklär werden.

Daß die Arbeiterklasse in einem antagonistischen Verhältnis zum Kapital steht, und auch der Versuch der Einschränkung ihrer Konkurrenz in den Gewerk- 
schaftsorganisationen auf die Dauer nicht die Sicherung ihrer Existenz, die Konkurrenz gegenuber dem $\mathbb{K}$ apital erlaubt, ist als massenhaftes Bewußtsein erst Resultat sich zuspitzender Auseinandersetzungen und der Erfahrung der Grenzen des organisierten Kampfes um die Sicherung und Verbesserung ihrer Lebensbedingungen innerhalb der kapitalistischen Produk tionsweise. (Wieweit dieses Bewußtsein selbst wieder durch die Organisationen des Proletariats als politisches vermittelt werden kann, von ihnen auch in Phasen des Kapitalwachstums repräsentiert werden kann, darauf wollen wir hier nicht eingehen.)

Revolutionäres Bewußtsein und revolutionäre Organisationen entwickeln sich unter der Bedingung des entfalteten Kapitalisnus erst im Prozeß der Auseinandersetzung mit dem Reformismus, welcher eben eine notwendige Bewußtseins- und Organisationsform der Arbeiterklasse innerhalb der bürgerlichen Gesellschaft darstellt, und dem sich - wie die Geschichte der kommunistischen Parteien nach dem Zweiten Weltkrieg zeigt-- auch Organisationen der Arbeiterklasse, die sich ursprünglich als revolutionäre begriffen, nicht einfach entziehen können, soweit in ihnen relevante Teile der Arbeiter organisiert sind.

\section{5}

Die Arbeiterklasse tritt in ihrer Konkurrenz mit dem Kapital und ihrem Versuch, durch gewerkschaftliche Organisation diese Konkurrenz überhaupt durchführen zu können, nicht von vomherein als einheitliche auf. Das Kapital produziert zum einen die Trennung zwischen körperlicher und geistiger Arbeit, es produziert die Arbeitsteilung und damit unterschiedliche Arbeitsfunktionen innerhalb des Produktionsprozesses (Teilung zwischen qualifizierten und unqualifizierten Arbeitern). Das Kapital delegiert im weiteren bestimmte seiner Funktionen an Teile der Lohnarbeiter (Aufsicht und Kontrolle). Im Prozeß der gesamtgesellschaftichen Reproduktion wird produktive und unproduktive Arbeit geleistet. Das Kapital agiert als konkurrierendes Einzelkapital innerhalb der einzelnen Branchen, und Konkurrenz der Kapitale findet statt, einmal innerhalb, zum zweiten zwischen den Branchen. Unterschiedliche Position der Einzelkapitale in der Konkurrenz schließt unterschiedliche Position der von ihnen beschäftigten Arbeiter ein.

Das Kapital produziert also die Lohnarbeiterklasse als in sich selbst wiederum differenzierte, welche Differenzierung sich auch in den gewerkschaftlichen Organisationen selbst wieder zunächst naturwüchsig niederschlägt. Dies ist ein wesentlicher Erklärungsgrund für die unterschiedlichen historischen Erscheinungsformen der Gewerkschaftsorganisation. So gibt es z. B. immer wieder Versuche qualifizierter Arbeiter, ihre Verkaufsbedingungen gegenüber dem Kapital zu verbessern, indem sie in ihrem Zusammenschluß sich selbst wieder gegenüber der Konkurrenz anderer Arbeiter abschließen. (Wir denken im folgenden an bestimmte Organisationsformen in den USA.) Hier wird also das Arbeitsangebot „künstlich" verknappt durch diese Form gewerkschaftlicher Organisierung. Durch die Kontrolle des Arbeitsmarkts für Arbeiter bestimmter Qualifikation soll dem Kapital Widerstand entgegengesetzt werden bei seinem Versuch, die Konkurrenz unter den Arbeitern als Mittel der 
Lohnsenkung und Erhöhung der Arbeitsleistung einzusetzen. Daher ist hier die gewerkschaftliche Organisation ein Mittel, die Konkurrenz gegenüber dem Kapital durch den Versuch des Ausschlusses der Konkurrenz unter den Arbeitern in der Form zu organisieren, daß sich Teile der Lohnarbeiter organisatorisch von der Masse der anderen Arbeiter abgrenzer. "Diese Organisationen (worunter alle stöndische Gewerkschaftsorganisationen, wie sie sich exemplarisch in den USA herausgebildet haben, fallen) neigen dann auch dazu, auf dem Verhandlungsweg mit dem Kapital zu verkehren, da die Machtposition gegenüber dem Kapital nicht durch Verweigerung der Arbeitsleistung, sondern durch die Absonderung von der Arbeiterklasse ausgetragen werden kann. (Allerdings werden diese Organisationsformen durch das wechselnde Bedürfnis des Kapitals nach A rbeitskraft bestimmter Qualifikation selbst immer wieder in Frage gestellt.) Daher körnen auch in dieser Form die Gewerkschaften nicht mehr als Klassenorganisationen fungieren, sondern schreiben eher die naturwüchsige Zersplitterung der Arbeiterklasse organisatorisch fort; sie sind dann nicht mehr Organ der Klasse gegen das Kapital, sondern Vertretung privilegierter Arbeiterschichten dem Kapital gegenüber - auf Kosten anderer Arbeiter.

Gewerkschaftliche Organisation bedeutet nicht notwendig Vereinigung aller Arbeiter gegenüber dem Kapital, vielmehr kann sich zwischen verschiedenen Ge werkschaftsorganisationen und innerhalb derselben selbst die Konkurrenz wiederum in der Form reproduzieren, daß Teile der Arbeiter sich monopolistisch gegenüber anderen Teilen der Arbeiter abzuschließen suchen.(Unter diesem Gesichtspunkt müßte auch das Verhältnis von Facharbeitern und einfachen Arbeitern in den BRD-Gewerkschaften diskutiert werden.) Monopol also als Form der Konkurrenz innerhalb der Arbeiterklasse (wenn auch immer nur voribergehend), über welches die Arbeiter einer bestimmten Qualifikation mit dem Kapital zu konkurrieren suchen. Solche Monopolbildungen reagieren auf das Gesetz, daß, je leichter der Übergang der Arbeiter von einem Produktionszweig zum anderen, von einer Arbeitsfunk. tion zur anderen, je größer die Konkurrenz unter ihnen.

Aber auch wenn eine gewerkschaftliche Organisation sich als Organisation aller Arbeiter herausgebildet hat, bleibt sie zunächst noch Organisation der nationalen Arbeiterklasse, sucht also die Verschlechterung der Lage der Arbeiterklasse durch Vermehrung der Konkurrenz unter ihnen dadurch aufzuhalten, daß sie sich z. B. gegen den Zustrom auslåndischer Arbeiter oder gegen den Abfluß von Kapital zur Wehr zu setzen sucht (Produktionsverlagerung, Kapitalexport).

Halten wir also fest: Gewerkschaftsorganisation impliziert die Einsicht der Arbeiter, daß sie nicht als einzelne mit dem Kapital konkurrieren können, bedeutet aber nicht notwendig Vereinigung der Arbeiter zur Klasse, welche die bewußte Einheit aller Arbeiter, auch die der Unbeschäftigten einschließt. Solche Formen gewerkschaftlicher Organisation sind selbst vielmehr schon Resultat eines politischen Bewußtwerdungsprozesses in welchem den Arbeitern die Einsicht aufgezwungen wurde, daß sie als Klasse dem Kapital gegenüberstehen mit historisch unversöhnlichen Widersprüchen. (Vgl. die Entstehung sozialdemokratischer und kommunistischer Gewerkschaften.)

Daraus ergibt sich aber auch, daß die Gewerkschaftsorganisationen, in wel- 
chen wenigstens formell die verschiedenen Schichten der Arbeiter vereint sind, welche sich also nicht durch Klassenzersplitterung in der Konkurrenz mit dern Kapital zu behaupten suchen, in diesem Punkt offener sind fïr ihre Transformation in Instrumente des allgemeinen Klassenkampfes mit dem Kapital, als solche historischen Organisationsformen, welche die Konkurrenz mit dem Kapital als Konkurrenz innerhalb der Arbeiterklasse lediglich reproduzieren (also alle ständischen Organisationsformen, Organisationen mit closed-shop-Prinzip, wie z. B. in den USA).

\section{6}

Beziehen sich die Arbeiter auf die Gewerkschaft als ihr organisatorisches Mittel, mit dem $\mathbb{K}$ apital zu konkurrieren, so isî dadurch umso mehr das Selbstverständnis der Gewerkschaft als Apparat bestimmt. Kem des gewerkschaftlichen Reformismas ist eben die Vorstellung, es bedurfe nur der Organisation, um dem Kapital die Sicherung der Existenzbedingungen der Arbeiter und einen Anteil aw wachsenden gesellschaftlichen Reichtum abzuzwingen. Gerade am Festhalten der Organisation als einem solchen Apparat der Interessendurchsetzung, an der Vorstellung, die Arbeiterinteressen ließen sich früher oder später durch die Organisation selbst durchsetzen, entwickelt sich der Widerspruch zwischen Arbeitern und historisch herausgebildeter Gewerkschaftsorganisation in Phasen, wo sich die allgemeinen Gesetze der kapitalistischen Produktion als krisenhafte Entwicklung der Lage der Arbeiterklasse und der Kapitalverwertung durchsetzen (\$). Während - wenn auch noch mehr oder weniger unbegriffen - der Widerstand der Árbeiter gegen eine Herabsetzung ihrer Lebensbedingungen auf den antagonistischen Charakter von Lohnarbeit und Kapital verweist, sichtbar macht, daß die Entwicklung des gesellschaftlichen Reichtums im Widerspruch zur Entwicklung der gesellschaftlichen Individuen sich vollzieht, wird die Gewerkschaftsorganisation, insofern sie sich eben begreift als entwickeltes organisatorisches Instrument der Konkurrenz zwischen Lohnarbeit und Kapital innerhalb der kapitalistischen Gesellschaft, weiterhin den Interessenausgleich zu organisieren suchen und sich damit in Widerspruch zur Bereitschaft der Arbeiter, für die Verteidigung ihrer Lebensbedingungen mit dem Kapital den Kampf aufzunehmen, setzer, (z.B., indem sie glaubt, durch Lohnstillhaltepolitik die Arbeitsplätze sichern zu können). Solange die Arbeiter selbst noch nicht das Bewußtsein der revolutionären Konsequenz aus ihrem Kampf mit dem Kapital heraushaben, wird zudem eine Politik der versuchten Klassenversöhnung von seiten des Gewerkschaftsapparats sich auf das noch unentwickelte und/oder diffuse Bewußtsein der Arbeiter von ihrer historischen Aufgabe stützen können. Auch das entwickelte Bewußtsein von der Unversöhnlichkeit zwischen $A$ ibeiter- und Kapitalinteressen bedeutet noch nicht, daß damit die Gewerkschaft einfach revolutionäre Organisation sein könnte. Solange es der Arbeiterklasse nicht gelungen ist, die gesellschaftliche Macht vollends zu ibernehmen, Bleibt die objektive Funktion der Gewerkschaft, die Ware Arbeitskraft zu verkaufen, bestehen.

Von da aus läßt sich zunächst grob bestimmen, daß zum einen der erscheinen-

entfällt 
de Widerspruch zwischen Arbeitern und historisch herausgebildetem Gewerkschafts" apparat als historische Erscheinung aus dem allgemeinen Verhältnis zwischen Lohnarbeit und Kapital herzuleiten ist, sich also nicht mit organisationssoziologischen (Bürokratiethese) oder moralischen Argumenten (Klassenverrat) einfach bestimmen läßt. Zurn anderen wird sichtbar, daß es durchaus ein Ziel sein kann, die Gewerk. schaften progressiv zw verändern und für die Besetzung von Machtpositionen durch Linke zu kämpfen. Mit dieser Veränderung darf allerdings nicht die lllusion verbunden sein, man habe nun die Gewerkschaft in eine revolutionäre Organisation verwandelt. Auch solche personellen Veränderungen würden nicht die Finktion der Gewerkschaft verändern können, Mittel der Arbeiter zu ihrer Konkurrenz mit dem Kapital zu sein und als solche eine Notwendigkeit für die Arbeiter darzustellen, um uberhaupt dem Kapital Widerstand leisten zu können. Die Gewerkschaft muß Verträge mit dem Kapital schließen können, in denen die Verkaufsbedingungen der Arbeitskraft festgehalten werden, solange die Ware Arbeitskraft verkauft wird. Sie mußs also vertragsfähig sein für das Kapital. Die Integration des Gewerkschaftsapparats ist Resultat dieser objektiven Funktion und nicht einfach nur das falscher Organisationsformen (mangelnde Demokratie, moralische Heruntergekomenenheit von Indiviauen). Vielmehr kann jede auf die Gewerkschaftsorganisation bezogene Strategie von Sozialisten und Kommunisten sich nur darauf richten, der Entwick. lung des Klassenwiderspruchs und des Klassenkampfs in der Gewerkschaft eine Bewegungsform zu geben, Gewerkschaftsorganisationen selbst zu Instrumenten des Klassenk ampfs zu entwickeln, die Entwicklung des Klassenwiderstands der Arbeiter überhaupt vermittelt über die Gewerkschaft zu organisieren. Dieser Widerstand selbst schwankt, solange die herrschende Klasse nicht gestürzt ist und die Produktionsverhältnisse nicht umgewandelt sind, immer zwischen den den Klassenantagonismus aufzeigenden Kämpfen und Kompromissen mit dem Kapital. Innerhalb der kapitalistischen Gesellschaft kann dieses Schwanken nur vom Kapital (bzw. dem bürgerlichen Staat) in seinem Sinne aufgehoben werden, mümlich durch die terrorstische Unterdrückung der Arbeiterklasse und die Zerschlagung ihrer Organisationen.

\section{7}

Zur Analyse reformistischen Bewußtseins der Apbeiter und reformistischer Organisationen der Arbeiterklasse reicht nun allerdings die Darstellung der mit dem Kapitalverhältnis gesetzten Verkehrungen der wirklichen (Ausbeutungs-)Zusammenhänge, der notwendig gesetzten Konkurrenz unter den Arbeitern und der historisch herausgebildeten Organisationsformen der Arbeiter nicht hin. Vielmehr ist ja jene Instanz, die wir oben als Instanz der herrschenden Klasse zur Zerschlagung der Arbeiterorganisationen (unter bestimmten historischen $B$ edingungen angedeutet haben, selbst noch A usgangspunkt von Illusionen: der Staat. Der A rbeiter ist nicht nur Warenverkäufer und Objekt der Ausbeutung, vielmehr isí er gerade als ,Teilnehmer" an, Handelnder in der Zirkulation auch Stautsbürger, freier und gleicher Teilnehmer am Tauschakt. Wir wollen diesen Zusammenhang hier kurz zu umreißen 
versuchen, weil daraus weitere Illusionen über die Lage der Arbeiter und deren Veränderung in der bürgerlichen Gesellschaft resultieren, die weiter unten bei Analyse des Verhältnisses von SPD und Gewerkschaften wichtig werden (6).

Dabei muß der Staat aus der Anatomie der bürgerlichen Gesellschaft in seinen Funktionen abgeleitet werden, will man die Möglichkeiten und Grenzen staatlichen Handelns und die Quelle illusionären Bewußtseins gegenüber dem Staat adäquat darstellen. Mit der Enitwicklung des Warentauschs ist auch die Entwicklung jener Instanz gesetzt, die die äußeren Bedingungen des $T$ auschs garantiert und -- versehen mit Sanktionsmitteln - als äußere Zwangsgewalt gegenüber den Teilnehmern am Austauschprozess diese generellen Normen auch geltend macht. Diese hier nur kurz benannte Funktion des Staates erfährt dann eine entscheidende Veränderung in ihrem Inhalt, wenn das Geld sich zum Kapital, die Arbeit sich zur Lohnarbeit entwickelt: Ohne daßs es besonderer ,never" Funktionen bedürfte, garantiert der Staat dann nicht mehr nur die Bedingungen des Austauschs, sondern in dieser Funktion zugleich auch und gerade die Bedingungen der Ausbeutung, insofern dieser Austausch nunmehr die Anwendung und Ausbeutung des Lohnarbeiters im Produktionsprozess einleitet. Damit ist zugleich der Staat als Klassenstaat definiert, eben weil er sich gegenüber Lohnarbeit und Kapital äußerlich verhält als Garant der Bedingungen des Austauschs der Ware Arbeitskraft mit dem Kapital: Gerade um Klassengewalt zu sein, muß sich der Staat Garant der Bedingungen des Austauschs der Lohnarbeit mit dem Kapital gegenüber dem Kapital. Wir haben hier also aus der Funktion des Staates als äußere Zwangsgewalt den Austauschenden gegenüber sowohl den ,Klassenstaat ${ }^{\text {" }}$ als auch den ,Sozialstaat " im Keim abgeleitet: Einerseits garantiert der Staat den Ausbeutungsprozeß, insofern er die Basis des Tauschs - das Privateigentum (hier: das Kapitaleigentum) - garantiert, und setzt die damit erfolgende Unterwerfung des Arbeiters unter das Kapital den Arbeitern gegenüber notfalls mit Gewalt durch. Andererseits garantiert er aber auch das ,Eigentum" des Arbeiters, die Arbeitskraft, sofern sie als Ware auf dem Markt auftritt und setzt damit dem Kapital Schranken in der hemmungslosen A usbeutung des Arbeiters.

Umgekehrt bezieht sich der Arbeiter als Verkäufer einer Ware auf die Zirkulationssphäre, die Sphäre der „Freiheit ${ }^{6 \varepsilon}$ und "Gleichheit" und bezieht sich in dieser Funktion als freier Staatsbürger auf den Staat. Einmal in den Produktionsprozeß eingetreten, endet die Sphäre der Freiheit und Gleichheit, beginnt die Herrschaft

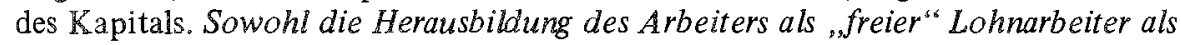
auch des Arbeiters als Staatsbürger sind allerdings Resultat von Klassenkämpfen, in deren Verlauf sich die Arbeiter auch die Anerkennung ihrer Koalitionen durch Kapital und Staat erkämpfen. Muindet dieser Prozeß nun in die Institutionalisierung des Klassengegensatzes, in die ,Verrechtilichung " der Beziehungen zwischen Kapital und Arbeit, so werden die Organisationen der Arbeiter zwar in das kapitalistische System, integriert ${ }^{\text {ts; }}$; diese Integration ist aber nicht Ausdruck eines wie auch immer

6) Wir beziehen uns in den folgenden Ausfuhrungen auf die $u$. E. fortgeschrittenste Ableitung der Staatsfunktionen bei: Bernhard Blanke, Ulrich Jurgens, Hans Kastendiek, Zur neueren marxistischen Diskussion über die Analyse von Form und Funktion des bürger* lichen Staats, Referat auf der Tagung der Deutschen Vereinigung für Politische Wissenschaft in Hamburg vom 1. bis 4. Oktober 1973; das Referat soll demnächst in einem Sonderheft der Politischen Vierteljahresschrift veröffentlicht werden. 
gearteten qualitativen Wandels in Verhältnis zwischen Lohnarbeit und Kapital (und der Rolle der Gewerkschaften darin), sondern Resultat der Anerkennung der Arbeiter und ihrer Organisationen als Warenverkäufer, insofern also dern kapitalistischen Produktionsprozeß funktional! Daß dieser Warentausch zugleich die A usbeutung des Arbeiters im Produktionsprozeß einleitet, setzt ja gerade jene Ronfikte in den Organisationen der Arbeiter und zwischen Gewerkschafien, Kapital und Staat, die unter bestimmter historischer Zuspitzung jene Integration wieder aujorechen oder doch zumindest brüchig werden läßt.

Wird so einerseits durch die Anerkennung des Arbeiters als Warenverkäufer und damit durch die staatliche Garantie seiner Verkaufsbedingungen die Illusion befördert, der Staat stehe über der Gesellschaft und könne durch einen entsprechenden Druck (sei es vermittels der Gewerkschaften, sei es vermittels politischer Parteien) zu einem Handeln gezwungen werden, das die Situation der Arbeiter grundlegend verändert, so gewinnt diese Vorstellung eine scheinbar äußerst reale Perspektive, wenn es den Arbeitern im Gefolge von Klassenauseinandersetzungen gelingt, als freie, gleiche, mit allen politischen Rechten ausgestattete Staatsbürger, anerkannt zu werden. Denn grundsätzlich ist damit zunächst jener Widerspruch jeder bürgerlichen Verfassung mit allgemeinen Wahlrecht gesetzt, der darin besteht, daß ,den organisierten 1 ohnarbeitem die politische Macht ohne die gesellschaftliche Macht gegeben ist, und den Kapitaleigentumern die gesellschaftliche Macht überlassen bleibt, aber ohne politische Garantie" (7). Zwar sind über die Teilhabe der Arbeiterklasse an der politischen Macht dem Klassenkampf - selbst wenn er sich in so unentwickelten Formen wie der Auseinandersetzung un die Verteilung des Sozialprodukts ausdrück $\hat{t}$ - grundsätzlich neue Daten gesetzt; aber gerade solche möglichen Teilerfolge lassen die Bedingtheit der staatlichen Politik durch die Gesetze der Kapitalreproduktion aus dem Blick schwinden. Die Durchsetzung dieser Gesetze wird durch die Funktion des Sîates, die $B$ asis des Austausches, das Privateigentum, zu garantieren, gewährleistet und es sinä ja gerade Arbeiterparteien gewesen, die unter der Parole antraten, den Staat dazu zu zwingen, die Gatantie der äußeren Bedingungen des Austauschs auch für die Ware Arbeitskraft geltend zu machen-gegeniber ders Kapital! Am Ende dieses Prozesses steht nicht die Erlangung der gesellschartlichen Macht vermittels des Staates, sondern die bürgerliche Reformpartei, die ihre Funktion nurmehr in der weiteren Ausdifferenzierung jener,, Zirkulationsrechte ${ }^{66}$ der Arbeiterklasse (die auch die Bedingungen der Anwendung der Arbeitskraft umfassen) zu sehen vermag.

Die reformistischen Voastellung der Arbeiter in bezug auf den Staat lassen

7) Wolfgang Müller, Der Pluralismus - die Staatstheorie des Reformismus, in: G. Doeker/W. S teffani (Hrsg.), Klassenjustiz und Pluralismus, Festschrift für E. Fraenkel, Hamburg 1973, S. 415. In diesem Aufsatz wird am Beispiel Naphtalis und Sinzheimers der gewerkschaftliche Feformismus in seiner Illusion, ibber den bürgerlichen Staat die Bedingungen des Austauschs Lohnarbeit-Kapital verändern zu können, anschaulich entwickelt. Voraussetzung des partiellen Erfolgs gewerkschaftlichen Reformismus (in dei Weimarer Republik) war bezeichnenderweise eine Phase relativ prosperierender Kapitalakkumulation und der vorangegangene Klassenkompromib nach 1918. Mit den ersten Krisenanzeichen werden dann auch die Teilerfolge durch den bügerlichen Staat zurickgenommen. 
sich so aus dem Wesen des kapitalistischen Stats materialistisch begrinden, nu setzt dieser Reformismas offensichtlich worats, das der Stat nicht gezwangen ist, offen zugunsten der Erhaltung des Privateigentums und chanit zugurster der Regrodiktion des Kapitals in die Reproduktionsbedingungen der Arbeiterkhsse eirzugret fen: sei es indrekt über die okonomische Politik des States (Statsinterventiontsmus, Einkonmenspolitik), sei es direkt wber die unverhillte Repression der Arbeiterklasse und ihrer Organistionen (wie dies am offensten in Faschismus der Fall ist). Der Grad dieses Eingriff zugursten der Enhalung der kapitalistischen Produktionsweise (deren Garant er ist) ist allerdings nicht mehr auf dieser algemeinen Ebene zu bestimmen, sondern hängt ab von den konkreten Bedingungen der Mehr. wertproduktion, der Akkumulation des Kapitals und der konkreten Bntwicklung des Klassenkampfs. Drant findet jedoch auch dos reformistische Bewugtsein eine Schranke in der Zuspitaurg der Konflikte im Akkumulationsprozeß, der verschäg.

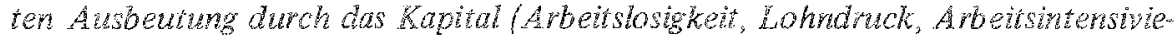
nung, offere Despotie des Einzelkapitalisien) und Unterdruckurg durch den statilichen Repressionsapparat. Auf diesem Hintergrund muß auch die Möglichke î́ der Auflosung von "arbeitsgeneingchaftichen Vorstellunger" oder die mögliche Auf kindigung einer Zusannenarbeit Staat/Kapital - Gewerkschaften gesehen werden.

\section{8}

Im Vertältnis zwischen Lohnarbeic und Kapital sind auch selbst de Bedingungen gesetzt, welche die Arbeiter darauf verweisen, die Gewerkschaften zu linstrumenter des offenen Klassenkampfs zu machen. Kann in Phasen prosperierender Kapitalakkumulation die Konkurrenz der Arbeiter mit dem Kapial vermittelt iber die Gewerkschaftsorganisationen zeitweise bürgerliche Formen annehmen (Reduktion auf Verhandlung, reine Stellvertreterpolitik der Arbeiterinteressen, repräsentatives Han deln), so zwingt der Versuch des Kapitals, seine wachsenden Verwertungsschwiergkeiten bei sich verengendem Spielraum der Akkumulation zu kompensieren durch Druck auf den Arbeitslohn und zunehmenden Druck auf die Arbeitsleising die Arbeiter dazu, dieser Tendenz Widerstand entgegenzusetzen. Thre Lebensinteressen geraten jetzt in offenen Widerspruch mit dem Verwertungsinteresse des Kapitals. Was als unterschiedliches (aber versöhnbares) Interesse erschien, kanr jetzt wieder die Form des offenen Klassenkampfes annelmen. Dies wird zum einen darin deutlich, daß das Kapital sich jetzt vom ,sozialpartnerschaftlichen Verhandungspartne ${ }^{66}$ zum organisierten Träger des Klassenkampfs von oben entpuppt und dabei den bügerlichen Staat (Polizei etc.) als Machtmittel einzuserzen sucht. Der Gegner wird damit als Klassengegner sichtbar. - Hält demgegenüber die Gewerkschaftsorganisa. tion noch an einer Politik der Klassenversohnung fest, so sind die Apbeier zunächst auf eine offene Austragung des Klassenkampfs mit dem $K$ apital hingewiesen, auf der Grundlage, die das Kapital selbst durch die Vereinigung der Arbeiter innerhalb dev Betriebe herstellt. Auf dieser betrieblichen Ebene können sie in spontanen Kämpfen Widerstand leisten. Doch die organisierte Macht des Kapitals wird jede mir auf den Betrieb bezogene Aktion auf die Dauer perspektivlos bleiben lassen und 
in unnötigen Niederlagen enden lassen.

Die Arteiter sind also gezwungen, sich die gewerkschaftlichen Formen der Organisation, auch wemn sie sich ihnen gegenüber verselbständigt haben, jetzt wieder zur Austragung des Gegensatzes zum Kapital in der Form des offenen Klassenkampfs anzueignen.

Auch das heißt noch nicht, daß damit automatisch schon die Erkenntnis der notwendigen Umwälzung der kapitalistischen Gesellschaft gesetzt ist. Auch das Austragen dieser Klassenkämpfe kann sich bei den Kämpfenden noch mit der Illusion verbinden, durch massiven Einsatz aller Kampfmittel die Lage der Arbeiterklasse gegenuber dem Kapital ohne Aufhebung der kapitalistischen Produktionsweise schrittweise und auf Dauer verbessern zu können. Andererseits ist klar, daß die Entwicklung der Gewerkschaften zu Kampforganisationen den bürgerlichen Staat als Maschineric der politischen Unterdiuckung auf den Plan ruft, je weniger die Interessen der kampfenden Arbeiter und die Notwendigkeiten der Kapitalakkumulation miteinander vereinbar sind. Auch Kämpfe, die unter reformistischen Vorzeichen begonnen und geführt werden, verweisen so auf ihre revolutionäre Konsequenz.

Die Gewerkschaftsorganisation wandelt sich also nicht in erster Linie deshalo zur Kassenkampforganisation, weil sich der Gewerkschaftsapparat als Instrument der Interesservertretung der Arbeiter legitimieren muß (er kann z. B. sagen, eine Lohnsenkung sei im Interesse der Arbeiter an der Erhaltung der Arbeitsplätze notwendig), sondern diesem Prozeß muß bei den Arbeitern selbst zugrunde liegen die Ekenntnis von der Notwendigkeit der Aneignung der Organisation als Instrument des Klassenkampîs, die Enkenntnis also, daß sie es sind, die sich in der Organisation organisieren und in ihe handeln.

\section{Zum gegerawartigen Stand der Auseinandersetzung der Arbeiter mit dem Kapidal und der Rolitik der Gewerkschaftsfuihrung}

Es ist im folgenden nicht möglich, eine Einschätzung des Stands der gesamien Gewerkschafts und Klassenbewegung in der BRD zu geben. Dazu müßten zum einen die Entwicklungen in den einzelnen Industriezweigen und den Einzelgewerk. schaften, das Problem der Cliederung der Lohnarbeiter, die Existenz einer breiten Schicht von Arbeitern, die nicht vom Kapital angewandt werden, sondern beim Staat angestelit sind, berucksichtigt werden; zum anderen müßs te die Ungleichmäßigkeit der Entwicklung der Klassenbewegung in den einzelnen Industriezweigen selbst charakterisiert werden. Hier soll es darum gehen, an der Entwicklung vor allem der 1G-Metall und hier wieder an ihren fortgeschrittensten Punkten Probleme aufzuzeigen, welche in bezug auf die Diskussion der Strategie des ,express ${ }^{66}$ - antikapitalistische Vertrauensleutestrategie -- uns wichtig erscheinen. 


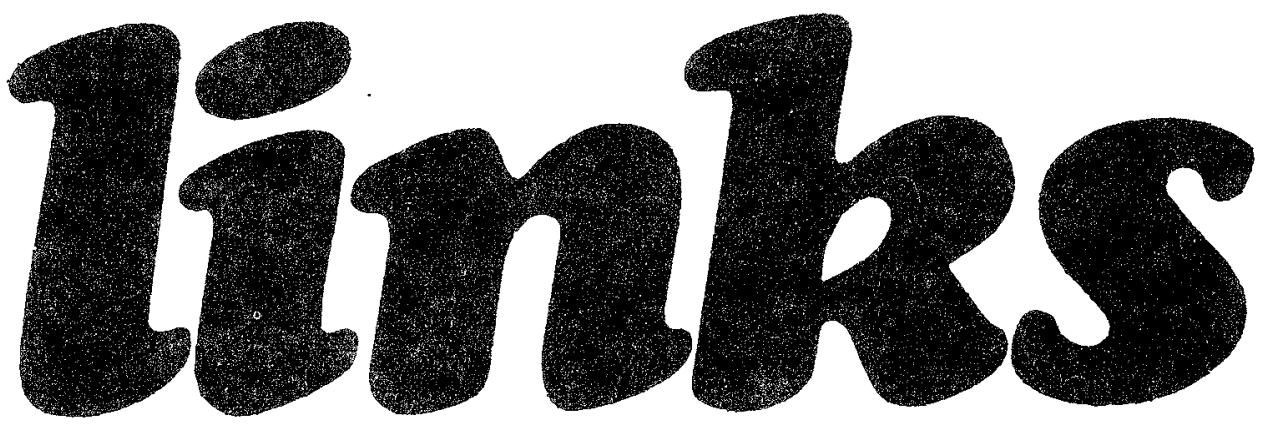

Sozialistische Zeitung

bring monaflich auf elwa 24 Seiten Aktionsmodelle, Beiträge zur sozialistischen Theorie und Sirategie, Berichte aus der Linken international. "links" ist illusionslos, undogmatisch - eine Zeitung für Theorie der Praxis und für Praxis der Theorie.

Einzelpreis DM 1.50.

Bezugspreis, jährlich, DM 18.- + DM 3.- Versandkosten

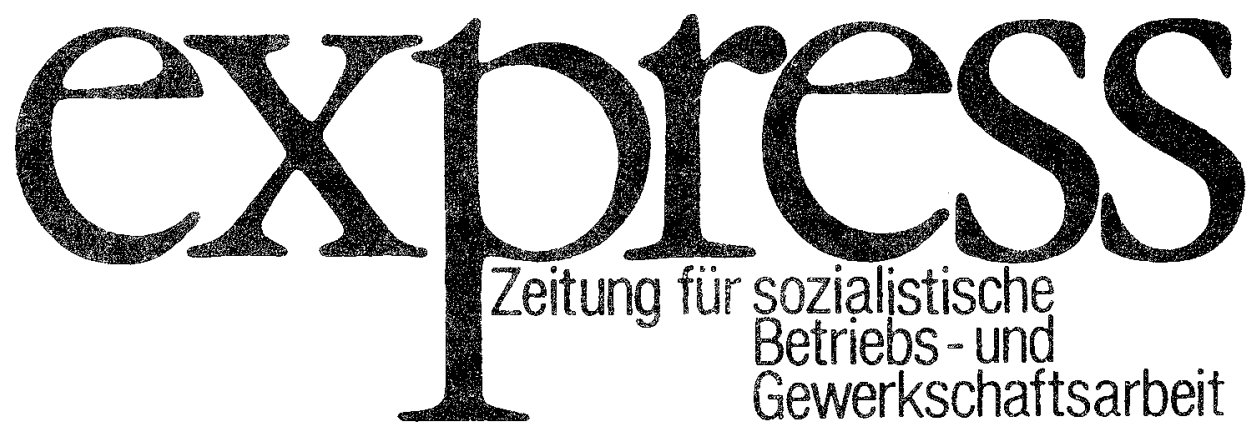

Sprachrohr der Kollegen und Genossen, die sozialistische Betriebsund Gewerkschaftsarbeit machen. Informationen über die Auseinanderselzung zwischen Kapital und Arbeit. Beiträge, die man nicht in den Gewerkschaftszeitungen findet.

Einzelpreis DM 1.-

Bezugspreis, jährlich, DM 14.- + 3.-Versandkosten

Probeexemplaie anfordern brw. Abonnementsbestellung bei Verlag 2000 GmbH. 605 Ottenbach Postach 591. 


\subsection{Veränderungen in der Kapitalakkumulation und den Klassenkämpfen seit 1967}

Die sich entwickelnden Auseinandersetzungen in den Gewerkschaften haben ihre Grundlagen in den veränderten Bedingungen im Kapitalwachstum und der damit veränderten Lage der A rbeiter seit Mitte der 60er Jahre. War mit dem ungehinderten Wachstum des Kapitals bis Mitte der 60er Jahre ein kontinuierlicher Anstieg der Reallöhne verbunden (was als eine materielle Grundlage des zunächst den Arbeitern nach 1945 aufgezwungenen Reformismus in den Gewerkschaften zu begreifen ist), können wir mit dem Eintreten der Krise 1966/67 Veränderungen in der Lage der Arbeiter feststellen, die ihre gesellschaftliche Stellung verschlechterten. Denn die veränderten Bedingungen im Wachstumsprozeß des Kapitals (die hier nicht näher ausgeführt werden können; vgl. dazu u. a. die Veröffentlichungen in der PROKLA Nr. 3, 4 und 5), zwingen die Kapitalisten, mittels Umwälzung der technologischen Basis der Produktion, veränderter Arbeitsorganisation und Intensivierung der Arbeit die Produktivkraft der Arbeit und somit die Mehrwertrate zu steigern. Andererseits führen der Druck der ,industriellen Reservearmee " (in der Krise), inflationäre Prozesse und die staatliche Einkommenspolitik $z u$ einem Druck auf die Lohnrate. Unmittelbare Folgen für die Lage der Arbeiter waren eine allgemeine Verunsicherung ihrer Existenz durch Frei- und Umsetzungen, Dequalifikationsprozesse sowie verschärfte Arbeitsbelastungen sowohl in der Krise als auch im Aufschwung und eine - relative - Verschlechterung ihrer gesellschaftlichen Stellung. Es können demgemäß zwei Ebenen beginnenden Widerstands der Arbeiter festgemacht werden:

In den Betrieben im wesentlichen als Widerstand gegen die Streichung übertariflicher Leistungen (vor allem in der Krise 1967 und dem Konjunkturabschwung 1971/72), gegen Verschlechterung der Arbeitsbedingungen, drohenden Verlust des Arbeitsplatzes, Lohnverschiedenheiten, Dequalifikationspro$z e s s e$. Als Ausgleich für reale Verschlechterungen in der Arbeitssituation werden dabei in der Regel zunächst Lohnerhöhungen gefordert. Überbetriebliche Kämpfe, welche die Arbeitsbedingungen unmittelbar zum Gegenstand haben, entwickeln sich erst in den letzten Jahren mit der Intensivierung der Arbeit. Gesamtwirtschaftlich entwickelt sich der Widerstand gegen die versuchte staatliche Einkommenspolitik (Konzertierte Aktion) als Forderung, die tariflichen Forderungen nicht an gesamtwirtschaftlichen Orientierungsdaten, sondern an den Lebensbedürfnissen der A rbeiter zu orientie ren.

Auf beiden Ebenen des beginnenden Widerstands wird die offizielle Gewerkschaftspolitik selbst zum Problem:

Aufgrund der bisherigen gewerkschaftlichen Praxis (wozu u. a. der Ausschluß der Kommunisten und linken Gewerkschafter bis in die Mitte der 50er Jahre zählt) sowie aufgrund der BetrVG und der auf ihm aufbauenden Rechtsprechung ist der Einfluß der Gewerkschaften in den Betrieben weitgehend begrenzt. Die Orientierung der Tarifpolitik an gesamtwirtschaftlichen Daten wird in der offiziellen Gewerkschaftspolitik selbst durchgesetzt. Sie erfordert wiederum eine Zentralisierung der Entscheidungsfunktionen. 
Die Abwehrkämpfe der Arbeiter entwickeln sich in der Krise zunächst als spontane Kämpfe gegen die Maßrahmen des Kapitals (bzw. gegen die Einzelmaßsnahrnen der Kapitalisten). Demgegenüber richten sich die Septemberstreiks 1969 nicht nur gegen das Kapital, sondern stellen auch eine Kritik der Gewerkschaftspolitik dar, insofern der Beitrit $t$ zur Konzertierten Aktion dazu gefuhrt hatte, daßs die im Aufschwung verbesserten Kampfbedingungen nicht für die Lohnpolitik genutzt wurden. So wie diese spontanen Streiks von der IG-Metall-Spitze noch als Resultat von Fehlern der Tarifpolitik interpretiert werden konnten, so wurden sie auf der anderen Seite von den Arbeitern und linken gewerkschaftlichen Kadern noch nicht als Ausdruck langfristiger Widersprüche zwischen Gewerkschaftspolitik und den Bedïrfnissen und Forderungen der Arbeiter begriffen, eher als Druck auf die Gewerkschaftsfuhrung, sich ihrer eigentlichen Aufgaben zu besinnen. Daraus ergab sich, daß - im Gegensatz zu den Jahren 1966-1969, wo Kämpfe der Arbeiter und der linken Gewerkschaftskader noch weitgehend neben der Politik der Gewerkschaften als Organisation herliefen - in der Tarifrunde 1970 die Bewegung an der Basis wieder weitgehend organisatorisch integriert werden konnte. Durch die offizielle Gewerkschaftspolitik wurde diese Bewegung z. T. in der Vorbereitung der Tarifrunde unterstützt. Auf ihrer Grundlage konnten relativ hohe Löhne gegeriüber dem Kapital durchgeselzt werden. So schien auf dem Höhepunkt der Konjunktur das ,gewerkschaftliche Monopol" auf Konfliktaustragung wieder gesichert.

Mochte nun auch das Kapital mit dieser Reintegration der spontanen Arbeiterbewegung zufrieden sein, so war doch ihre Bedingung, nämlich die Durchsetzung größerer Lohnerhöhungen, eine voribergehende. Die Tarifunden der IG-Chemie und der IG Metall im Jahre 1971 sind durch eine bis dahin unbekannte Vorbereitung der Arbeitgeberverbände der Chemie- und Metallindustrie auf eine harte Auseinandersetzung mit den Gewerkschaften im Zeichen der sich abschwächenden Konjunktur und der Weltwährungskrise gekennzeichnet. Mit ihren provozierenden Lohnangeboten scheren die Unternehmerverbände selbst aus der Konzertierten Aktion aus. Während Veränderungen im Charakter der Lohnauseinandersetzungen bis dahin auf die Metallindustrie beschränkt waren, breitet sich die Streikbereitschaft jetzt aus. In der Chemieindustrie findet der erste Streik in der Geschichte der BRD statt. Mit dem niedrigen Lohnabschluß setzt sich die Gewerkschaftsführung in Gegensatz zu den Betrieben, welche den Streik getragen hatten, kann sich allerdings mit der mangelnden Unterstiitzung des Streiks durch die Betriebsräte einiger Groß. unternehmen herausreden. In der Metallindustrie führt die provozierende Politik von Gesamtmetall (bis hin zur Ablehnung des Schiedsspruchs des Schlichters in NW/NB) zu einer außerordentiichen Streikbereitschaft der Arbeiter. So wie die IG-Metallführung die provozierende Politik von Gesamtmetall in der Vorbereitung der Tarifrunde nicht entsprechend beantwortet hatte, so war sie jetzt auch nicht bereit, die in der gesamten BRD vorhandene Streikbereitschaft als Kampfmittel in der Tarifrunde einzusetzen. So wurde der Abschluß nach dem Streik. in Baden-Württemberg $z$ war von Teilen der Arbeiter als politischer Erfolg gewertet, rief andererseits jedoch Unzufriedenheit und Protest gegen die mangelnde Ausnutzung der Streikbereitschaft bei der Durchführung der Tarifrunde hervor.

Hatten die Erfahrungen der Krise 1966/67 und des Erfolge 1970 die Gewerk. 
schaftsbewegung insgesamt gestärkt, indem das Bewußtsein von der Notwendigkeit einer starken Kampforganisation gegen das Kapital sich bei den Arbeitern wieder verstärkt hatte, so machen die streikbereiten Arbeiter 1971 erstmals massiv die Erfahrung, daß das Handeln der Gewerkschafsführung eine wirkliche Schranke ihrer Kampfkraft und -bereitschaft bildet. Diese Erfahrung setzt sich in der Tarifauseinandersetzung 1972/73 fort und vertieft sich in den spontanen Streiks im Jahre 1973 in der Metallindustrie (vgl. dazu genarer: PROKLA Nr. 10, Neue Momente in der Klassenbewegung 1973 in der Metallindustrie):

Die Arbeiter machen die Erfahrung der offenen Distanzierung der Gewerkschaftsführung vom Streik.

- Zunehmend werden die unteren Schichten der Arbeiterklasse initiativ. Das Kapital versucht, Spaltungen zwischen deutschen und ausländischen $A$ rbeitern zu bewirken.

- Die Forderungen der Arbeiter orientieren sich nicht mehr so sehr an der Proportionalität der Verteilung des produzierten Werts (vgl. demgegenüber noch Begründungen der Forderungen in den Septemberstreiks), sondern an der Reproduktion der Arbeitskraft, und zwar sowohl in bezug auf die Arbeitsbedingungen im Betrieb (Kampf gegen die Ausraubung der Arbeitskräfte, gegen hochdifferenzierte Lohnsysteme etc.) als auch in bezug auf die Lohnhöhe (Teuerungszulagen). Der Klassengegensatz wird damit sichtbarer.

Neben Erfolgen müssen die Arbeiter auch die Erfahrung schwerer Niederlagen machen, die Erfahrungen einer außerordentilch harten Strategie des Kapitals bis hin zum Polizeieinsaiz. Besondere Momente der Kapitalstrategie sind: Versuche, den Avantgardebetrieben Niederlagen zuzufugen (Mannesmann, Klöckner, Hoesch), die Abspaltung der Stahlindustrie von der Metallindustrie, die Zersplitterung der Streiks, keine Zugeständnisse an die Gewerkschaftsführung zu machen und der Einsatz von Meistern und Vorarbeitern etc. als Streikbrecher, der massive Einsatz der Arbeitsgerichtsbarkeit.

- Die Kampfbereitschaft der A rbeiter ist entwickelter als in den Septemberstreiks: Es kommt, trotz Niederlagen z. B. in den Avantgardebetrieben zu immer neuen Streiks auch in Betrieben, wo bisher nicht gestreikt wurde; die Streiks sind länger und ausdauernder, obwohl sie oft ohne die organisierende Kraft traditionell linker Kader und gegen das Votum der Gewerkschaftsfühnung durchgeführt werden. Es gibt Betriebe, wo kommunistische Gruppen auf den Streik Einfluß gewinnen, vor allem dort, wo ausländische Arbeiter streiken; positiv bei Hella/Lippstadt, mit negativer Auswirkung bei FORD. Hier stellt sich das Problem selbständiger Streikleitungen im Falle des Versagens der betrieblichen Gewerkschaftsorgane.

- Die Auseinandersetzung mit der SPD wird offener: Die SPD stößt mit ihrer wirtschaftspolitischen Konzeption an die Grenzen der kapitalistischen Ökonomie: Das Dilemma von Inflation (= Druck auf Reallohn) und A rbeitslosigkeit wird zugunsten einer harten Stabilitätspolitik entschieden, ohne damit die Inflation zindämmen oder die Gefahr der Arbeitslosigkeit (gerade in ,strukturschwachen ${ }^{6}$ Bereichen) beseitigen zu können. Die Illusionen in die sozialdemokratische Wirtschaftspolitik bröckeln ab; zudem ist die SPD dort, wo sie in 
den Ländern Regierungspartei ist, gezwungen, sogar die Polizei gegen die Streiks aufzurüsten oder (wie in Nord rhein-Westfalen) gegen Streikende einzusetzen. In den Mitbestimmuıgsbetrieben spielen die SPD-Arbeitsdirektoren eine reaktionäre Rolle während der Streiks (z. B. bei Klöckner). Angesichts dieser Situation muß die Propagierung der Mitbestimmung durch die SPD ein Schlag ins Wasser werden, kann keinerlei propagandistische Kraft mehr entfalten, was die Präsentation der SPD als Arbeitnehme rpartei angeht.

Diese Momente der Verschärfung des Klassenkampfes, der Entwicklung verstärkter Kampfbereitschaft und der Vertiefung innergewerkschaftlicher Widersprüche zeigten sich vollständig und unverschleiert in den spontanen Streiks der Metallindustrie. In den Organisationsbereichen anderer Gewerkschaften, vor allem der IG-Chemie, der IG-Bergbau und der IG-Druck und Papier, manifestiert sich zwar erhöhter Kampfwille, jedoch gelang es den Gewerkschaftsführungen mit unterschiedlichen Mitteln - Auffangen durch Vorpreschen bei der DRUPA, offene Einschüchterung der Streikenden bei der IG-Bergbau - die offene Austragung von Konflikten zu verhindern.

In der Druckindustrie hatten die Mitgliederversammlungen fast aller größeren Drupa-Ortsvereine im Januar/Februar Forderungen nach linearen Lohnerhöhungen von $40 \mathrm{DM}$ wöchentlich und Preisgleitklauseln aufgestellt. Der Hauptvorstand beschloß, um Dampf abzulassen, eine zwar prozentuale, aber über den Metall-Abschluß weit hinausgehende Forderung (13\%) und versuchte zugleich, aktive Gruppen in den Betrieben durch einen Extremistenbeschluß - den ersten im DGB - einzuschüchtern. Als ein Streik unausweichlich wurde, versuchte der Hauptvorstand ihn auf 2 Stunden pro Schicht zu begrenzen, tatsächlich aber wurde in den meisten Zeitungsdruckereien länger gestreikt. Der 10,8-Prozent-Abschluß stieß zwar auf starken Widerstand in den Betrieben (Gegenstimmen bundesweit $44 \%$, im Bezirk Frankfurt z. B. $73 \%$ ), er war aber hoch genug, um Proteststreiks und autonome betriebliche Kämpfe vorerst weitgehend zu verhindern.

In der Chemieindustrie blieb die Opposition gegen den nach dem Druckabschluß erfolgten 9,9-Prozent-Abschluß auf den Bezirk Rheinland-Pfalz mit dem Zentrum BASF beschränkt, wo im April erstmals große Teile der Belegschaft streikten und einen Abschluß über $10 \%$ durchsetzten. Insgesamt aber wird die Entfaltung von Lohnkämpfen in der Chemieindustrie weiterhin einerseits durch die Allianz von Betriebsräten und Unternehmensleitungen in den großen Konzernen (besonders hohe Differenz zwischen Effektiv- und Tariflöhnen), andererseits durch die extrem enge Bindung des Gewerkschaftsvorstands an die SPD erfolgreich behindert; auch die satzungsmäßige Verankerung der Vertrauensleute hat daran nichts ändern können.

Im Bergbau lieferte der Saar-Streik vom Oktober ein Exempel erfolgreicher gewerkschaftlicher und staatlicher Disziplinierungspolitik, zugleich Exempel der Unzulänglichkeit rein spontaner, nicht von Kadern organisierter Kampfführung. Eine fugenlose Einheit von Gewerkschaftsspitze, staatlichem Unternehmer und Massenmedien brachte den Streik von 13.000 Bergleuten binnen 2 Tagen zum Scheitern. Dies war umso leichter möglich, weil den Streikenden trotz DKP.Unterstiutzung auch die einfachsten organisatorischen Voraussetzungen (Streikposten, Ver- 
bindungen der Betriebsbelegschaften untereinander, Kommunikationsmittel) fehlten. Trotz branchenspezifischer Unterschiede lassen sich zwei generelle Ursachen für das Zurückbleiben der Kämpfe in den genannten Bereichen hinter dem Metallbe. reich ausmachen:

Die IG-Metall hatte durch ihren stabilitätskonformen 8,5-Prozent-Abschluß vom Januar, der mit zwei Dritteln Gegenstimmen quittiert wurde, in ihrem Bereich friiher als alle anderen Gewerkschaften das Bewußtsein von der Notwendigkeit des betrieblichen, außergewerkschaftlichen Abwehrkampfes gegen Lohnraub und Verschärfung der Arbeitsbedingungen aktualisiert, während die anderen Gewerkschaften diese Unzufriedenheit durch spätere und höhere Tarif-Abschlïsse partiell abfangen konnten.

- Der Metallbereich ist aufgrund der traditionellen Vorreiterrolle der IG-Metall der kampferfahrenste, was die Konsequenz hat, daß Metallarbeiter als erste ihre Kampfformen auch außerhalb und gegen die Gewerkschaftsführung weiterentwickeln, andererseits auch die Metall-Unternehmer besser als andere die Anwendung ebenso differenzierter wie brutaler Klassenkampfmethoden lernen konnten.

Gerade in der Metallindustrie laufen die Erfahrungen der Arbeiter auf eine Enttäuschung hinaus. In ihrem Bewußtsein hat die gewerkschaftliche Organisation ein Kampfinstrument zu sein, das den Streikwillen der Arbeiter in Streikaktionen umsetzt. Tut die Gewerkschaft dies nicht und finden selbständige Kämpfe statt, so drängt sich den Arbeitern die Notwendigkeit, die Gewerkschaft zu verändern, umso mehr auf, je weniger es ihnen gelingt, durch rein betriebliche, ohne die Gewerkschaft geführte Streiks Erfolge gegenüber dem Kapital zu erzielen. In dem Maße, wie der Klassengegner sichtbar wird, wie eine Strategie des Kapitals, die Kämpfe in den Betrieben zu zersplittern und als vereinzelte zu zerschlagen, offen hervortritt, erscheint der auf den einzelnen Betrieb beschränkte Kampf nicht mehr als jederzeit mögliches Mittel der Interessendurchsetzung und der praktischen Kritik der offiziellen Gewerkschaftspolitik. Die Erfahrung verweist auf die Notwendigkeit, die Gewerkschaft als Klassenkampfinstrument zu entwickeln. Sie spiegelt sich in der Entwicklung von Forderungen der Gewerkschaft gegenüber, die auf ihre innere Demokratisierung hinauslaufen (Veränderung des Urabstimmungsmodus, Stärkung der Stellung der Vertrauensleute in den Tarifkommissionen, Verlagerung von Verhandlungskompetenzen auf die betriebliche Ebene).

Das Kapital tritt zwar zunehmend als Klassengegner ins Bewußtsein, aber damit muß nicht notwendig schon die kapitalistische Produktionsweise als Schranke der Sicherung der Lebensbedingungen erscheinen. Zunächst kann durchaus der konkrete historische Zustand der Gewerkschaftsorganisation und dann auch die konkrete Politik des bürgerlichen Staats Ansatzpunkt des sich entwickelnden kritischen Bewußtseins sein.

Die Erkenntnis von der Notwendigkeit der Demokratisierung der Organisation bedeutet dabei zunächst die Überwindung einer Schranke im Bewußtsein der Arbeiter selbst, nämlich der Vorstellung, per Delegation der Interessenwahrnehmung an die Gewerkschaftsorganisation oder die Betriebsräte sei ihre gesellschaftliche Stellung zu verteidigen. $\mathrm{Zu}$ fragen bleibt, wie in diesem Lernprozeß die Erkenntnis der 
Unversöhnlichkeit der Klassengegensätze sich vermittelt, wie sie vermittelt werden kann?

In unseren anfänglichen Thesen haben wir versucht, Momente aufzuzeigen, aus denen heraus eine sozialistische Position bestimmt werden könnte. Wir sehen uns nun nicht in der Lage, unmittelbare Handlungsrezepte für eine sozialistische Gewerkschaftsstrategie zu liefern, etwa in der Art der, antikapitalistischen Vertrauensleutestrategie ${ }^{65}$. Im folgenden führen wir nur einige Überlegungen an, auf deren Grundlage die Diskussion weitergeführt werden kann, vor welchen Problemen und Aufgaben gegenwärtig eine sozialistische Gewerkschaftsarbeit steht und wel. chen Stellenwert Einzelkonzepte eben wie z. B. die antikapitalistische Vertrauensleutestrategie haben. Eines kann nach dem Vorhergehenden schon gesagt werden: Gerade die Liquidierung der Traditionen einer kommunistischen Partei in der BRD durch den auch von der SPD und den sozialdemokratischen Gewerkschaften getragenen Antikommunismus führt dazu, daß die beschriebenen neuen Entwicklungen der Klassenkämpfe zunächst ein radikal-reformistisches Bewußtsein als gegenwärtig fortgeschrittenste Form innerhalb der traditionell an der SPD orientierten westdeutschen Arbeiterklasse hervorbringen kann, was sich dann aber auch resignativ wenden kann, wem sich ihm keinerlei politische Handlungsperspektiven bieten. Es ist also zu diskutieren, ob Sozialisten auf dieses Bewußtsein sich in der Weise beziehen, daß sie es in seiner gegebenen Form aufnehmen und bestätigen, oder ob es nicht notwendig ist, von vornherein die erfahrenen Widersprüche als widersprïche einer Gesellschaft aufzuzeigen, die selbst die Bedingungen ihrer notwendigen Limwälzung aus sich heraustreibt. Von uns wird die letztgenannte Position vertreten. Anders gesagt: Die Unversöhnlichkeit der Klassenwiderspriche kann nicht erst dam propagiert werden, wenn jede reformistische Variante der Arbeiterpolitik in die Niederlage gefiihrt hat.

Die Frage bleibt aber auch dann noch offen, wie jeweils im einzelnen die Vermittlung stattfindet zwischen ,Reform und Revolution", in der Analyse des historischen Prozesses und in den Organisationsformen der Arbeiterklasse.

\section{Die ganze linke literatur}

auch in Städten und Dörfern ohne sozialistische Buchhandlung, durch den Postversand des
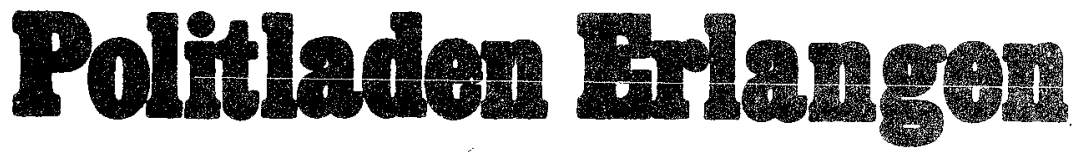

Klassiker des Marxismus, Theorie der Neuen Linken, heprints unk Archive, Geschichte der Arbeiterbewegung, Internationaler Kagsen. kampf; Bücher, Broschüren, Infos, Plakate und Schallplasten der sozialistischen Verlage des Ir - und Austandes.

Versandlisten anfordern! Auslieferung aller Bestellungen portofrei auf Rechnung.

Postanschrift: POLITLADEN 852 ERLANGEN POSTFACH 2849 


\subsection{Einige A spekte des Verhaltnisses von Gewerkschaften und SPD}

\subsubsection{Krisenmanipulation und bürgerlicher Staat}

Muß auf der einen Seite eine auf die innergewerkschaftliche Demokratisierung gerichtete Politik von dem Bewußtsein getragen sein, daß sich diese nur über die Stärkung der selbständigen Kampfrăhigkeit der Arbeiter überhaupt durchsetzen laßkt, so muß auf der anderen Seite der antagonistische Interessengegensatz zwischen Lohnarbeit und Kapital, so weit er sich in den gegenwärtigen Erfahrungen und Kämpfen der Arbeiter niederschlägt, herausgearbeitet werden. Dies schließt eine Auseinandersetzung mit allen Vorstellungen ein, welche die tatsächliche Lage der Arbeiterklasse aus der Willkur der Kapitalisten, aus der fehlerhaften Politik einer sozialdemokratischen Regienung, aus der mangeinden Mach tentfaitung der Arbeiterklasse innerhalb dieser Gesellschaft abzuleiten suchen. Zwar ist davon auszugehen, daß die tatsächliche Lage der Arbeiter auch ein Ergebnis der tatsächlichen Macht. entfaltung und Kampáfähigkeit ihrer Organisation ist. (Vgl. dazu genauer 3.) Aber die Kritik und Auseinandersetzung mit der SPD und der Gewerkschaftsfihmung kann nicht in der Weise verlaufen, daß als Resultat dieser Kritik neue lllusionen in die Versöhnbarkeit der Klasseninteressen bei entsprechender Machtentfaltung der Arbeiterklasse innerhalb der kapitalistischen Gesellschaft herausspringen.

Das bedeutet $\mathrm{z}$. B., daß man nicht versucht, die Tatsache, daj3 das kapiralistische System mit innerer Nonwendigkeit Krisen produziert, denen auch der kapitalistische Staat nicht daueshaft beikommen kann, dadurch wegzuinterpretieren, daj man die Krise als rom Kapital manipulierte darstellt, als pfiffige Erfindung der Kapitalisten womöglich noch zusammen mit dem bürgerlichen Staat, um die Arbetter zu disziplinieren (8). Das bedeutet z. B., daß man bei der Auseinandersetzung mit der SPD.Regierungspolitik es nicht dabei beläßt, ihr vorzuwerfen, sie vertrete nicht die Interessen der Arbeiterklasse, sondern selbst Ilusionen als solche deutlich rilacht, welche große Teile der Arbeiter an die SPD binden: die lllusionen von den Möglichkeiten des staatlichen Krisenmanagements; die Illusion, Lohnverzicht ermögliche den Arbeitern z. B., ihre Arbeitsplätze dauerhaft zu sichem. Man kann solche Illusionen durchaus zi destruieren suchen, und zwar anhand der inneren Tendenzen im Akkumulationsprozeß, die von den Arbeitern als Druck auf den

8) Vgl. dazu die Interpretation der gegenwärtigen Krise (Anfang 1974) durch O. Jacobi in ,express ${ }^{6}$ (Nov. 1973) und ,links" (Jan. 1974): Wird die Krise nicht mehr als notwendig aus dem kapitalistischen Reproduktionsprozeß abgeleitet, sondern als Krise überhaupt nicht gnehr wahrgenommen (weil man eine Krise nur an den Wachstumsraten des Brittosozialprodukts festzumachen vemag), kann die nicht $z u$ leugnende Arbeitslosigkeit auch nur noch als "Kollektivstrafe " der Untemehmer für die unbotmäßigen Arbeiter begriffen werden. Dagegen könnten die Gewerkschaften auf die ankurbelnde Kraft statlicher Wirtschaftspolitik vertrauen. Deshalb: eine känpferische Tarifpolitik ist notwen. dig! - Eine solche ist freilich immer vonnöten, das Problem ist doch gerade, dies den von Arbeitslosigkeit bedrohten und von der Inflation betroffenen Arbeitern einsichtig zu machen (bzw. eine solche Einsicht argumentativ zu stützen) und darin zugleich Momente eines Bewuftseins zu vermitteln, das über den gewerkschafthchen Kampf im Kapitalis. mus hinausweist, indern man Krisen als notwendiges Resultat der Kapitalreproduktion aufdeck 
Reallohn, Verschlechterung der Arbeitsbedingungen und Arbeitsplatzunsicherheit, sowie anhand der tatsächlichen Mißerfolge z. B. der SPD-Regierungspolitik und ihrer inneren Widersprüche, erfahren werden. Dabei ist es die Aufgabe einer sozialistischen Propaganda, an diesen realen Problemen der Arbeiter anknüpfend diese als notwendige Resultate des kapitalistischen Produktions- und Akkumulationsprozesses darzustellen, um darin die Perspektive der Übenwindung des Kapitalverhältnisses vermitteln zu können. Ohne eine solche Perspektive werden die Arbeiter immer wieder zurückgeworfen sein in die reformistische Illusion, im Kapitalismus ihre Lage grundlegend verändern zu können. Denn dient demgegenüber eine positive Einschätzung der Möglichkeit von Kapitalisten und Staat, die Krise zu manipulieren, gar als Basis einer sozialistischen Politik in den Arbeiterorganisationen, dann kann allerdings der Kampf nur noch als Konfrontation der organisatorischen Vertretung der Arbeiter mit der organisatorischen Vertretung der Kapitalisten begriffen werden; vom Ausgangspunkt dieser Auseinandersetzung, die durch die jeweilige Macht der Organisation entschieden wird, hinge dann allein das Schicksal der Arbeiter ab. Denn wenn Kapitalisten und Staat die Krise manipulieren können, muß man sie auch zwingen können, zuzusichern, den Fortgang der Akkumulation und damit die Sicherheit des Arbeitsplatzes, die Umverteilung der Einkommen oder gar die Kontrolle der Investitionen zuzugestehen (9).

Unter der Hand geraten so alle Illusionen sozialdemokratischer Herkunft unter dem Mantel einer solchen ,Machttheorie“ zur ",sozialistischen" Politik. Man spiegelt so den Arbeitern vor, sie könnten Subjekt der gesellschaftlichen Bewegung im Spätkapitalismus sein, wenn sie nur wollten: Sei es durch Machtentfaltung gegen das Kapital im Betrieb und durch die Gewerkschaft, sei es durch Druck auf ihre Partei, eine Politik im Interesse der Arbeiter zu machen.

Die Konsequenz einer solchen Konzeption führt zu einer Politik, die nicht nur theoretisch falsch, sondern auch politisch gefährlich ist, weil sie die Arbeiter hilflos jeder Form der Propaganda von einer besseren Politik des kapitalistischen Staates, wie sie auch von den bürgerlich-reaktionären Parteien vorgetragen wird, aussetzt. Die Nichthinwendung zur CDU überläßt man dem Klassengefühl und begibt sich der Möglichkeit, die Erkenntnisse, welche anhand des wirklichen Versagens der SPD-Politik über den Charakter des bürgerlichen Staates gewonnen werden könnten, auch nur ansatzweise zu fördern.

\subsubsection{Zu den Konflikten zwischen Gewerkschaftsführung und SPD-Regierung}

Mit sich entwickelnder Krise können immer häufiger Konflikte zwischen Gewerkschaftsführung und SPD-Regierung beobachtet werden. Die Vertreter der Gewerkschaften können sich bezüglich der notwendigen Höhe von Lohnforderungen immer seltener mit Regierungsvertretern einigen, die Maßnahmen zur Sicherung der Ar-

9) Wir werden die theoretischen Fehler und politischen Implikationen solcher linksbürgerlichen Theorien, die lediglich das Verhältnis von Lohn und Profit und nicht mehr die Kapitalreproduktion als Totalität als Krisenerklärung heranziehen, anhand einer Dokumentation einer Kontroverse in der britischen Linken zwischen A. Glyn/B. Sutcliffe und D. Yaiffe in einer der nächsten Ausgaben der PROKLA darstellen! 
beitsplätze werden in ihren Auswirkungen immer öfter verschieden beurteilt.

Im Zusammenhang mit diesen sich häufenden Konflikten wird nicht selten die Hoffnung laut, daß die enge Bindung der Gewerkschaftsführung an die sozialdemokratische Parteiführung sich aufzulösen beginnt und der Anfang eines Ablösungsprozesses der nach links orientierten reformistischen Gewerkschaften von der bürgerlichen Reformpartei SPD zu erkennen sei, der zugleich den linken reformistischen Flügel in der SPD gegenüber den bürgerlichen Reformern stärkt. Werden die Ursachen dieser Konflikte untersucht, erweisen sich diese Hoffnungen als illusionär.

Sozialdemokratie und Gewerkschaftsführung haben sich mit ihrer Theorie in der bestehenden bürgerlichen Gesellschaft eingerichtet. Sie wollen Auswïchse mit staatlichen Eingriffen bekämpfen und durch Lohnkämpfe eine gerechte Verteilung erreichen. Mehr als die Gewerkschaftsführung hat dabei die Mehrheit der sozialdemokratischen Parteiführung auch ferne Sozialismusvorstellungen über Bord geworfen. Trotzdem bestehen in der Theorie kaum Widersprüche. In der Praxis sieht es etwas anders aus. Die Gewerkschaften sind, auch wenn sie sich als reformistische Organisation verstehen, gezwungen; durch Organisierung von Lohnkämpfen zu versuchen, einen Lohnabbau zu verhindern. Das setzt voraus, daß die Gewerkschaften zumindest partiell an den Interessen der von ihnen organisierten Arbeiter anknüpfen und die Verbindung zur gewerkschaftlichen Basis nicht verlieren. Das gilt für die Gewerkschaften in Phasen konjunkturellen Aufschwungs ebenso wie in der Krise. Auch eine Sozialdemokratie in der Opposition kann, ein abstraktes Gemeinwohl ohne Konsequenzen postulierend, so agieren, daß die Lohnabhängigen sich von ihr vertreten fühlen.

Anders sieht es jedoch aus, wenn die Sozialdemokratie in der Regierung politische Macht mit ausübt. In der Regierungsverantwortung ist die SPD der Funktion des bürgerlichen Staates unterworfen, die Venwertungsbedingungen des Kapitals zu garantieren, bzw. abzusichern zu suchen. In Phasen rascher Kapitalakkumulation en tstehen dadurch nur wenig Probleme, da sich das Kapitalin teresse durchaus verbal mit dem sozialdemokratischen Gemeinwohl vereinbaren läßt.

Engt sich dagegen der Akkumulationsspielraum des Kapitals ein, so muß auch eine sozialdemokratisch geführte Regierung, da sie eine radikale Veränderung der Produktionsverhältnisse aus ihrer Politik ausgeschlossen hat, die Garantie der Verwertungsbedingungen des Kapitals auch gegen die Interessen der Arbeiterklasse durchzusetzen suchen. Der Unterschied zu einer von der CDU/CSU geführten Regierung, der nicht gering zu achten ist, besteht darin, daß die SPD mehr als jene bereit ist, den Versuch zu wagen, die gröbsten Auswirkungen der Krise auf die Arbeiterklasse zu vermindern. Für die Gewerkschaften werden dagegen in der Krise die engeren Bindungen der Organisation an die Arbeiterklasse wirksam. Der Spielraum, über Arbeiterinteressen hinwegzugehen, ohne daß es der Mehrheit der Organisierten bewußt wird, wird geringer.

Hier lassen sich für das Verhältnis Gewerkschaftsführung - SPD folgende Thesen entwickeln.

Zwei mögliche Verhaltensweisen der Gewerkschaftsführung schälen sich mit sich zuspitzender krisenhafter Entwicklung je nach Einschätzung der Kampfbereitschaft der Basis und nach dem Grad der Verquickung von Gewerkschaftsspitze und 
SPD-Führung heraus. Sie bedeuten beide ein zumindest äußerliches Abrücken von der zwischen Lohnarbeit und Kapital scheinbar friedlich-schiedlich vermittelnden Position der Gewerkschaften, und zugleich deutet sich hier die Möglichkeit einer Fraktionieiung innerhalb der Gewerkschaftsfuhrungen selbst an, die allerdings nicht als prinzipieller Gegensatz interpretiert werden darf:

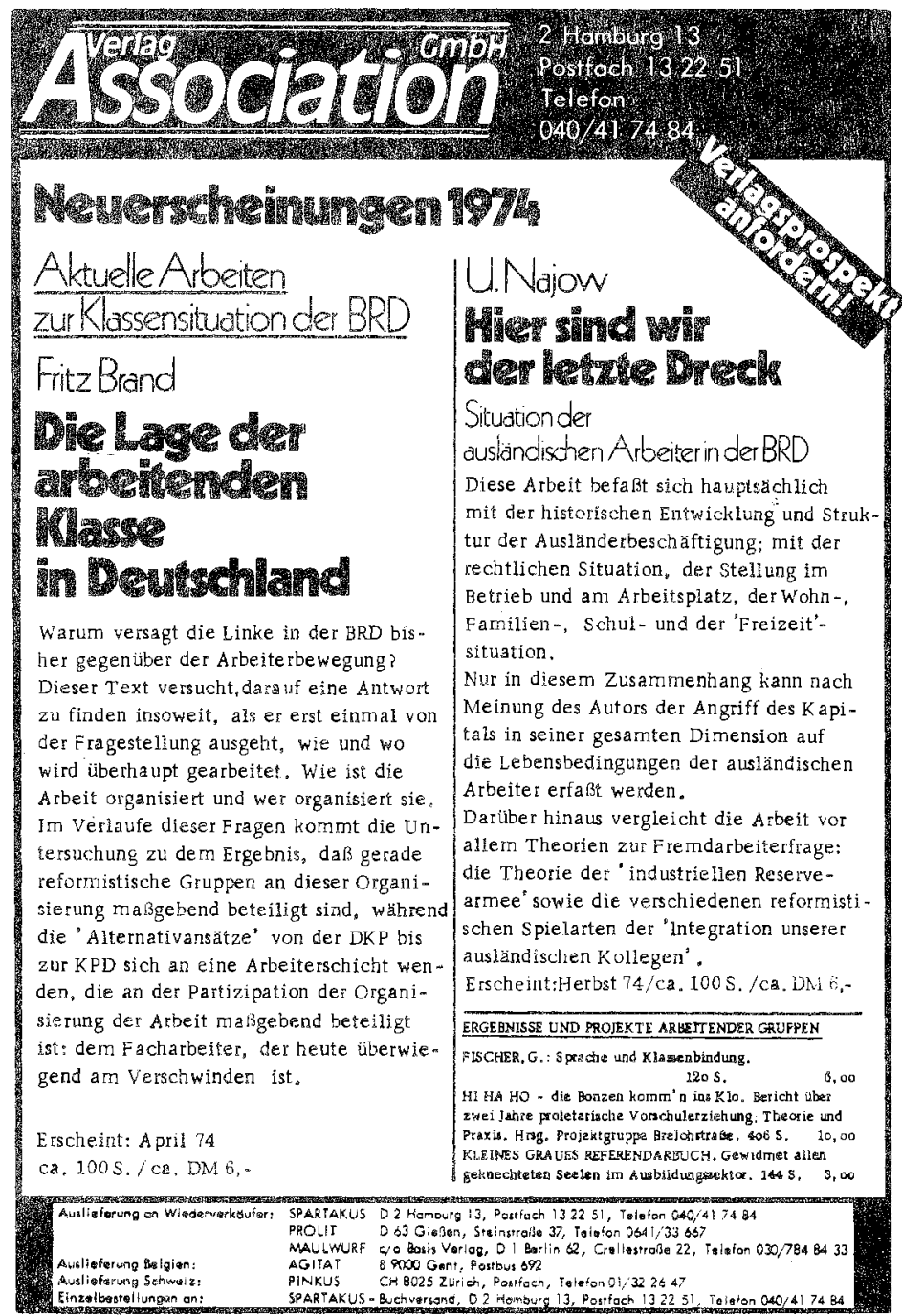


1. Die Gewerkschaftsfiuhmung schlägt sich mit brutaler Offenheit aü die Seite der sozialdemokratischen Vollstrecker des Kapitalinteresses und unterdrückt im Verein mit staatlicher Bürokratie, Unternehmensfuhrung und Polizei alle Formen der Auflehnung der Gewerkschaftsbasis und der Nichtorganisierten gegen die Verschlechterung der Lebensbedingungen der Arbeiterklasse (vgl. etwa IG-Bergbau). Die Gefährdung der Organisation durch diese Taktik wird entweder nur gering geachtet oder bewußt in Kauf genommen, zumal selbst ein solches Abwürgen etwa von Lohnkämpfen sich noch auf die Vertretung der Arbeiterinteressen - z. B. Sicherung der Arbeitsplätze - beruft.

2. Die Gewerkschaftsführung (meist auch subjektiv ehrich die Arbeiterinteressen vertreten wollend) wird wegen der drohenden und von ihr ernst genommenen Abkehr der Basis von der Organisation zur Aufstellung von Forderungen veranlaßst, die einen Konflikt mit der SPD-Regierung bedeuten können. Das geschieht aus der Überlegung heraus, daß die Gewerkschaften, gerade wenn sie als reformistische Gewerkschaften verstanden werden, gezwungen sind, sich als kampfbereite, Lohnkämpfe durchstehende Organisationen zu erweisen. Die Gewerkschaftsführung erreicht das, indem sie einerseits am Interesse der Arbeiter orientierte Forderingen aufstelit, die den Maßhalte. appellen der SPD-Regierung deutlich widersprechen und sie durch Streikdrohung und Streik durchzusetzen sucht, andererseits aber auch mit aller Energie zu verhindern trachtet, daßs die daraus erwachsenden Kämpfe selbständigen, den Rahmen der Planung durch die Gewerkschaf tsfïhrung sprengenden Charakter annehmen. Auch dieses Verhalten der Gewerkschaftsfihrung bringt der Arbeiterklasse selbst wenig Erfolge; die Organisation ist jedoch in geringerem Maße geschwächt.

Die zweite mögliche Verhaltensweise der Gewerkschaftsfihrung ist die Ursache von möglichen Konflikten zwischen Gewerkschafts- und SPD.Fuhrung. Sie durfen jedoch nicht in der Weise mißinterpretiert werden, als wäre mit solchen Konflikien von der Seite der Gewerkschaftsführungen schon ein entscheidender Schritt vorwärts hin zur Gewerkschaft als autonomer Klassenkarmpforganisation getan. Zum einen dient die Austragung der Konflikte von Seiten der Gewerkschaftsfühungen allein dem Ziel, die Gewerkschaft in ihrem gegenwärtigen Zustand zu erhalten, d. h. auch jeden Versuch der Gewerkschaftsbasis, sich die Organisation als ein Instrument des Klassenkampfs anzueignen, abzuwehren. Zum andern wird der Konflikt in dem Moment beendet sein, in dem entweder die SPD wieder in der Opposition ist oder der Akkumulationsprozeß wieder partielle Zugeständnisse an die Lohnarbeiter erlaubt.

Immerhin kann festgehalten werden, daß solche Konflikte den Aktions- und Agitationsspielraum linker Gewerkschaftskader - aber nicht nur dieser - erweitem, 2. B. den Agitationsspielraum darüber, wie die SPD Arbeiterinteressen vertritt, wenn es hart auf hart kommt. 


\subsubsection{Zum Verhältnis von Sozialdemokratie, SPD-orientierter Gewerkschaftspolitik}

und Arbeiterschaft

Wenn die Trennung von Ökonomie und Politik, die von der kapitalistischen Gesellschaft stets reproduziert wird, die illusionäre Vorstellung von staatlichen Handeln, daß von ökonomischen $Z$ wängen relativ frei sich entfalten könnte, erlaubt, so ist eine auf dieser Basis formulierte, ,sozialistische" Politik deswegen gefährlich, weil sie der Arbeiterschaft die Erfahrung des Scheiterns solcher Politik des Staates an den ökonomischen Zwängen überläßt und so zur Desorientierung beiträgt. Mit dem Eintritt der SPD in die Regierung waren bei den Arbeitern offensichtlich Vorstellungen vorhanden, daß die sozialdemokratische Regierungspolitik Veränderungen im gesellschaftlichen Gefüge zugunsten der Arbeiter durchsetzen könnte. Wenn nunmehr über die Erfahrung von Inflation und drohender Arbeitslosigkeit diese Erwartung nachhaltig enttäuscht wird, vielmehr die SPD offensichtlich nicht einmal besser als die CDU die ökonomischen Probleme zu lösen versteht, so ist darin die Möglichkeit eingeschlossen, daß sich Arbeiter sogar jener Partei (erneut?) zuwenden, die Repräsentant einer prosperierenden Phase der ökonomischen Entwicklung zu sein scheint. Auch in dieser Hinwendung der CDU wird - wenn sie partiell erfolgt - noch davon ausgegangen, daß es für den Staat möglich sei, die Ökonomie zu beherrschen und dab es offensichtlich das Versagen der jeweiligen Regierungspartei ist, das die Krise und Verschlechterung der Lage der Arbeiter herbeigeführt hat.

Es gehört nun zum gewerkschaftlichen Reformismus, daß (statt durch eigene Aktionen) Veränderungen über die Gesetzgebung der sozialdemokratischen Regierung erwartet und so wesentliche Interessen, deren Wahrnehmung und Durchsetzung, an die sozialdemokratische Regierung delegiert werden. In der Hoffnung der Wahrnehmung dieser Interessen durch die SPD hat die Gewerkschaftsorganisation daher den Kampf darum nicht entíalten wollen; gleichzeitig wird aber von den Arbeitern eine Verschlechterung ihrer Lage erfahren, die in einem offenen Gegensatz zu den Erwartungen in die Gewerkschafts- und SPD-Politik gerät: Die Zurückhaltung der Gewerkschaft setzt sie nun (unter diesen veränderten ökonomischen Bedingungen) in Gegensatz zu ihren Mitgliedern, die durch die Vermeidungsstrategie der Gewerkschaftsführung keine Kampfperspektive gegen das Kapital haben entwickeln können, wodurch die Bedingungen solidarischen Kampfes gegen das Kapital in der gegenwärtigen Phase enorm verschlechtert wurden. Zwar haben die spontanen Streiks dafür ansatzweise eine solche Perspektive aufweisen können, doch ist ein wesentliches Kennzeichen der 73 er Streiks gerade deren fehlende Transformierung in eine Machtposition gegen das Kapital durch die Gewerkschaften. Die Erfahrung der teils durch die Gewerkschaftsführung mitbewirkten Zersplitterung und der zeitlichen Verzögerung der einzelnen Kämpfe, also die Erfahrung einer relativen Ohnmacht gegenüber dem Kapital (auch gegenüber dem Gewerkschaftsapparat, was die Organisation der Kämpfe anbelangt), bestimmt offensichtlich auch die gegenwärtige Einschätzung der Arbeiter in vielen Betrieben, dies umso mehr, als der Druck des Kapitals auf die Arbeiter durch die drohende Arbeitslosigkeit gegenwärtig zunimmt und das Kampfrisiko erhöht.

Das Vertrauen in die SPD-Regierung schließt aber die eigene Entmündigung, 
als Arbeiterklasse im Kapitalismus gegen die Verschlechterung der Reproduktion der Arbeitskraft kämpfen zu müssen, ein. Führt dies - wie auch gegenwärtig - darüberhinaus zu einer Anpassung der Lohnpolitik der Einzelgewerkschaften an den durch die veränderten Akkumulationsbedingungen verringerten Lohnkampfspielraum traditioneller gewerkschaftlicher Lohnpolitik, so bedeutet dies den Verzicht auf eine effektive Interessenvertretung der Arbeiter gegenüber dem Kapital. Die Enttäuschung unter den Arbeitern über die Folgen solcher an der Regierungspolitik der SPD orientierten Lohnpolitik bleibt aber nicht ohne Folgen für gewerkschaftliches Handeln der Mitglieder überhaupt. Denn fehlt die geeignete Artikulationsund Organisationsform für den kämpferischen Einsatz für die eigenen Interessen, dann kann eine Reduktion gewerkschaftlicher Aktivität unter den Arbeitern nicht ausgeschlossen werden. Die Resignation unter Teilen der Arbeiter wäre (und ist teilsweise) Resultat der wahrgenommenen Nichtexistenz der Gewerkschaft als Kampforganisation.

Die Arbeiter sehen sich also ihrer Handlungsperspektive beraubt; insofern die gewerkschaftliche Aktivität nicht mehr die Erfahrung kämpferischer Solidarität zu vermitteln imstande ist, sind sie der durch das Kapital gesetzten Konkurrenz untereinander eher ausgeliefert gerade in einer Phase der ökonomischen Entwicklung, in der sich diese Konkurrenz objektiv verschärft und in Einzelfällen bis zu rassistischen Vorurteilen (zwischen Deutschen und Ausländern) führen kann.

Sowohl das Fehlen von Solidarität der Gewerkschaftsführung den spontanen Streiks gegenüber wie auch die äußerst wirksame Repression in der Gewerkschaft gegen linke Gewerkschaftskader oder den in den spontanen Streiks aktiv Beteiligten, oder gar die schlichte Rechnung der Gewerkschaftsführung den Mitgliedern gegenüber, daß sich ein Streik ja gar nicht lohne, verstärken die Verunsicherung gegenüber dem Streik ais Kampfwaffe gegen das Kapital und insgesamt gegenüber dem Streik als Kampfwaffe gegen das Kapital und insgesamt gegenüber einer konsequenten Vertretung der Arbeiter durch die Gewerkschaftsorganisation (9a). Das Zusammentreffen der Erfahrung relativer Ohnmacht und Desorientierung hinsichtlich der Möglichkeiten gewerkschaftlichen Kampfes und der gleichzeitig wieder betriebenen Delegation von Interessenvertretung an die SPD-Regierung kann aber zur hilflosen sozialpartnerschaftlichen Anpassung führen. Eine solche Verunsicherung gegenüber der gewerkschaftlichen Aktivität kann daher die Arbeiter auf das dichotomische Bewußtsein (das unveränderliche ,oben-unten ${ }^{6}$ ) zurïckwerfen oder darin bestätigen. Die beobachtbare reale Angst der Arbeiter vor einer weiteren Verschlechterung ihrer Lage liefert die Arbeiter angesichts der desorientierenden Gewerkschaftspolitik eher der bürgerlichen Propaganda aus als in Zeiten konkreter Erfahrung der Solidarität und daran geknüpfter organisatorischer Perspektiven der

9a) Vgl. dazu die Ereignisse in der IG-Metall in Bayern Anfang des Jahres; die Arbeiter kritisierten dort die Streikaufforderungen der IG-Metall: Plötzlich träte die Gewerkschaft für Streiks ein, obwohl ihnen früher von der Gewerkschaftsführung in verschiedenster Weise dargestellt worden wäre, daß Streiks so arg viel auch nicht nützten und daß sie eher als möglichst vermeidbares letztes Mittel anzusehen seien. Auf Versuche der IG-MetallFunktionäre, Warnstreiks zu organisieren angesichts einer sich verschärfenden Politik des Kapitals, reagierten die Arbeiter abweisend mit Argumenten wie: "Wie habt ihr's letztes Jahr mit den spontanen Streiks gemacht?" und: „Es ist ja schon alles gelaufen!" 
Arbeiterbewegung. Wird also die Interessenvertretung der Arbeiter streng „ökonomisch begrenzt, der politische Zusammenhang ausgeklammert und einer femen und unkontrolliebaren Institution unterworfen, verbleibt den Arbeitem nur ein diffuser, beliebiger, weil im Grunde doch nichts ändernder Protest. Sie sind ohne Kampfiritel auf die Rolle raisonnierender biurgerlicher Individuen beschrankt.

\subsection{Rlassenbewegung in der BRD und Ansatzpunkte sozialisischer Gewerk- schaftsarbeit}

Die gegenwärige Situation, vor die linke Gewerkschafter sich gestellt sehen, muß auf dem Hintergrund der Klassenkampfentwicklung seit 1969 betrachtet werden.

Die spontanen Streiks im Jahre 1969 zeigten zwar den Widerspruch zwischen offizieller Gewerkschaftspolitik und Arbeiterinteressen auf, aber keinejwegs als einen dauerhaften. Die Gewerkschaftsfuhrung nahm die Strcikbewegung unmittelbar auf, und erzielte in Verhandlungen mit dern Kapital Erfolge. Für die klassenbewißten Gewerkschafter mußte so zunächst die Vorsiellung entstehen, eine an den Klasseninteressen orientierte Poiltik könne durchgesetzt werden, und zwar iber die Gewerkschaftsorganisation, wenn nur jeweils genügend Druck von unten ausgeibt werde. Die Briche innerhalb der Organisation blieben verdeckt.

So konnte auch das in langen Jahren der Prosperität des Kapitals und der Stagnation der Klassenkämpfe entwickelte Verhältnis zwischen klassenbewurben Gewerkschaftern in den Betrieben (Betriebsräten und Vertrauensleuten) und Beleg. schaften zunächst beibehalten werden: eine Vorstellung, die davon ausgeht, die Durchsetzung der Arbeiterinteressen sei abhängig von einer an diesen Enteressen orientierten harten Vertreterpolitik der unteren Gewerkschaftsorgane. Ler Spie1. raum, welchen der Konjunkturaufschwung des Kapitals nach 1967 eneut bot, ermöglichte zudem nach wie vor Erfolge einer solchen Vertreterpolitik innerhalb der Betriebe.

Die Auseinandersetzungen innerhalb der Betriebe richteten sich demgenäß im Gefolge von Konflikten mit dem Kapital und mit rechten Betriebsräten und Vertrauenslenten auf deren Ersetzung durch klassenbewußtere Arbeiten. Die Frage der Durchsetzung der Arbeiterinteressen erschien zunächst vor allem abhängig von sozialpartnerschaftlicher oder an Klasseninteressen orientierter Politik. (Vgl. auch die Veränderungen, welche die Betriebsratswahlen 1972 zugunsten der Linken in einigen Betrieben brachte und die Auseinandersetzungen um die Aufstellung der Wahllisten.)

Strategien wie Stärkung der Stellung der Vertrauenskörper innerhalb der Gewerkschaftsorganisation ebenso wie die der betriebsnahen Tarifpolitik sind darauf gerichtet, die vorhandenen Potenzen klassenbewulter Gewerkschafter in der Orga. nisation zur Geltung zu bringen, die Orientierung der Gewerkschaftsfuhrung an der Rücksichtnahme auf die SPD als Regierungspartei zu durchkreuzen und auf diese Weise die Gewerkschaft selbst zu stärken. Zwar wird die Notwendigkeit der ,Nobilisierung der Basis ${ }^{65}$ dabei als wesentlicher Faktor beachtet, aber diese Mobilisierung selbst wird eher als Resultat guter Gewerkschaftspolitik begriffen, denn als Resultat 
der wirklichen Veränderungen in der Lage der Arbeiter. Die gleiche Richtung hat die Forderung nach allgemeiner Demokratisierung der Organisation. Die mangelnde Kampibereitschaft der Gewerkschaftsfuhrung erscheint als eine institutionell innerhalb der organisation zu überwindende Schranke, z. B. durch Erzielung von Mehrheiten auf den Gewerkschaftstagen -

Die materielle Grundlage der beginnenden Widersprüche zwischen Teilen der Arbeiterklasse, Kadem aus den Betrieben und der örtlichen Ebene und der Gewerkschaftsfihrung gerat in diesen Strategien weniger als Blickfeld. Nämlich die Einengung des Spielraums, welche die sich herausbildenden stagnativen Tendenzen in der Rapitalakkumulation jü Verbesserungen in der Lage der Arbeiterklasse innerhalb der bestichenden Verhaltnisse erzeugen. Der Widerspruch zwischen den Zielen einer an den Arbeiterinteressen orientierten Politik und der an der SPD als Regierungspartei onentierten Politik der Gewerkschaftsführung wird als Problem innerer Strukturen der Organisation und des Willensbildungsprozesses gefaßt - und weniger als Problem des sich entwickelnden und in Erscheinung tretenden Widerspruchs zwischen Kapitalakkumulation und Bedürnissen der Arbeiterklasse.

\section{Exkats: Zut betriebsnahen Tarifpolitik}

Da die vorliegenden Thesen zur Gewerkschaft im Zusammenhang mit einer Diskussion innerhalb des Sozialistischen Büros und mit der Redaktion von ,express" entstanden sind, ist es sinnvoll, an einem Punkt genauer die vom ,express ${ }^{66}$ entwickelten "Ansatzpunkte einer sozialistischen Betriebs- und Gewerkschaftsstrategie" zu untersuchen.

Als Ziel einer solchen Strategie wird in einem Thesenpapier zu der genannten Konferenz folgendes angegeber: "Es gilt, die von den Gewerkschaften nicht oder nicht zureichend aufgegriffenen Interessen und Bedürfnisse der Lohnabhängigen zur Grundlage gewerkschaftlicher Poli ik und damit die Gewerkschaften zu einem wirksamen Instrument der Lohnabhängigen zur Durchsetzung ihrer Klasseninteressen zu machen." (Wir zitieren hier und im folgenden aus dem Informationsrundbrief des Soz. Euros Nr. 2/1974) Als wichtigste Elemente einer solchen Strategie werden angegeben:

,1. Der Aurbau und Ausbau einer starken gewerkschaftlichen Vertrauensleutebewegung;

2. Der Kampf fur eine betriebliche (sprich auch betriebsnahe) Tarifpolitik

3. Die Durchseizung und Verbreiterung betrieblicher Bildungsarbeit

4. Die Entwicklung der Gewerkschaften zu autonomen Klassenorganisationen." Wesentliches allgemeines Kennzeichen einer solchen Strategie ist zunächst, daß sie an dern von uns beschriebenen Bewußtsein ansetzt, die konkrete organisatorische Verfassung des Gewerkschaftsapparats, die mangelnde Demokratie, die fehlende Rückkoppelung zwischen betrieblicher Basis und Gewerkschaftsapparat bilde eine wesentiche Schranke der Durchsetzung der Interessen der Arbeiter. Denn Inhalt der sozialstischen Gewerkschaftsstrategie soll ja schließlich sein, die Gewerkschafterl zv einem wirksamen Instrument der Vertretung der Klasseninteressen zu 
machen. Dieses Bewußtsein selbst wird nicht noch einmal kritisch hinterfragt, sondern durch die angegebenen Ziele, aber auch durch die Mittel ihrer Durchsetzung, närnlich gewerkschaftsinterne Veränderungen, bestätigt. In einer Art Stufenplan wird dann fortgegangen: „Als autonome Klassenorganisationen vermögen die Gewerkschaften wieder zu ,Schulen des Sozialismus' zu werden. "Anders gesagt: Zunächst sind durch die genannten Strategien 1-3, die Gewerkschaften als autonome Klassenorganisationen zu entwickeln, ist man so weit, ist also das Ziel erreicht, so beginnt die zweite Stufe: Gewerkschaften als Schulen des Sozialisinus. Wie dann konkret diese zweite Stufe auszusehen hat, wiro nicht angegeben. Allerdings lebt schon die erste Stufe von der Vorstellung, es bedürfe nur der Entwicklung kämpferischer Gewerkschaftspolitik, um die Interessen der Arbeiter innerhalb des Kapitalismus erfolgreich zu vertreten. Träfe dies zu, so ist allerdings unklar, wie selbst als autonome Klassengewerkschaft die Organisation zur ,Schule des Sozialismus ${ }^{6}$ werden soll, denn wie sollen die Gewerkschaftsmitglieder zur Erkenntnis der notwendigen Aufhebung der kapitalistischen Produktionsweise kommen, wenn schon ihre Kampfentfaltung innerhalb der bestehenden Verhältrisse zur Sicherung ihrer Lebensbedingungen zu führen vermag? Geht man allerdings davon aus, daß auch die Entwicklung einer kampffähigen Organisation, ihre Demokratisierung, durchaus verbunden ist mit Niederlagen gegenüber dem Kapital (betrachtet man nur einmal primär die Erreichung inhaltlicher Ziele: Erhöhung der Reallöhne, Sicherung der Arbeitsplätze, Verbesserung der Arbeitsbedingungen, Verbesserung der allgemeinen Lebensbedingungen, vgl. SB-Rundbrief), so ist wiederum nicht einzusehen, warum erst auf dern ohnehin nur abstrakt gesetzten Stadium der ,autonomen Klassenorganisation ${ }^{6}$ die Gewerkschaften zu Schulen des Sozialismus werden sollen. Geht man davon aus, daß die Demokratisierungsforderung selbst schon Resultat von Grenzen gewerkschaftlicher Politik zur Sicherung der Lebensbedingungen der Arbeiterklasse, wie sie durch die historische Entfaltung des Kapitalverhältnisses gesetzt sind, ist, so isi nicht einzusehen, wieso nicht schon innerhalb des Kampfes um die Demokratisierung der Organisation, entwickelt in Zusammenhang der Klassenauseinandersetzungen mit dem Kapital, das Bewußssein in die wirklichen Grenzen gewerkschaftlicher Politik sich entwickeln soll. Der Stufenplan ist also uneinsichtig.

$\mathrm{Da}$ die Klassenbewegung in der Konzeption des Redaktionskollektivs ,ex-

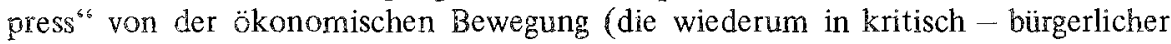
Weise als Resultat der manipulativen Kraft von Staat und Monopolen begriffen wird) getrennt wird, stellt sich für das Redaktionskollektiv die Machtfrage in folgender Form: Der Macht von Staat und Kapital muß die Macht der Arbeiter gegenubergestellt werden, um Staat und Kapital zu zwingen, eine Politik im Interesse der Arbeiter zu machen oder doch zumindest diesen Interessen nicht zuwider zu handeln. Da man aber zuvor Kapitalbewegung und Arbeiterklasse getrennt hat, muß sich diese Macht der Arbeiterklasse und ihrer Organisationen ,autonom" entwickeln, wird also nicht mehr in ihrem Zusammenhang mit der Kapitalentwicklung gesehen. Das Problem ist dann, wie diese Macht herstellbar ist! Die Antwort geben Modelle gewerkschaftlicher Strategie, die diese Mobilisierung zu leisten haben, wenn sie in die Praxis umgesetzt werden können. Damit ist also zunächst noch nicht der Inhalt dieser Strategien kritisiert, sondern der u. E. falsche Bezugspunkt. 
a) Betriebsnahe Tarifpolitik als Modell der Mobilisierungsstrategie in den Gewerkschaften

Versuchen wir das Problem zu konkretisieren anhand der vorgeschlagenen „betriebsnahen Tarifpolitik" im ,express"-Papier zur Februarkonferenz des Sozialistischen Büros. An diesem Beispiel soll vor allem der ahistorische Modellcharakter solcherart Strategievorschläge gezeigt werden. In ihrer Begründung findet auch eine kurze Auseinandersetzung mit der Kritik von links an dieser Strategie statt: ,Wie die Erfahrungen gezeigt haben, ist eine solche Tarifpolitik nur gegen den harten Widerstand der Unternehmer, der Mehrheit der Betriebsräte und großer Teile des Gewerkschaftsapparats durchzusetzen, so daß bereits die Mobilisierung für derartige Ziele und der Kampf um ihre Durchsetzung einen Kampf für die Verbesserung der innergewerkschaftlichen Demokratie und der Bildung von Klassenbewußtsein darstellt.

Die Befürchtung, eine derartige Tarifpolitik zerstöre die Solidarität zwischen den Beschäftigten eines Wirtschaftsbereiches, weil sie die traditionell oder aus anderen Gründen kampfstärkeren Belegschaften noch mehr begünstige, ist entgegenzuhalten, daß es gerade das derzeitige System der Betriebsvereinbarungspolitik ist, das diesen Zustand ständig herbeiführt und befördert, während betriebsnahe Tarifpolitik durch die Verbesserung der gewerkschaftlichen Kampfkraft die Chance bietet, günstigere Kampfbedingungen für alle zu schaffen." Dieser Argumentation liegen zunächst of fensichtlich Fehleinschätzungen zugrunde, die wiederum aus dem grundsätzlichen methodischen und inhaltlichen Vorgehen innerhalb der ,express' Thesen entspringen: nämlich am vorhandenen Gewerkschaftszustand, statt am vorhandenen Verhältnis zwischen Lohnarbeit und Kapital anzusetzen. Zum einen ist eine Strategie von vornherein zum Scheitern verurteilt, die institutionelle Veränderungen der Gewerkschaftspolitik zum Kampfgegenstand zu machen sucht, für diese ,mobilisieJen" will, statt von der ,Mobilisierung der Arbeiter durch ihre tatsächliche Situation auszugehen und, im Zusammenhang von Kampferfahrungen um inhaltliche Forderungen, denn auch bestimmte institutionelle Forderungen zu entwickeln. Um dies an einern Beispiel klarzulegen: In der Chemietarifrunde 1970 versuchte die IG-Chemie, eine Strategie betriebsnaher Tarifpolitik durchzusetzen. In Hessen wurden betriebliche Tarifkommissionen gebildet und man versuchte, das Kapital zu zwingen, mit diesen zu verhandeln und Verträge abzuschließen. In Rheinland-Pfalz kommt es, entgegen innergewerkschaftlicher Absprachen, zu einem verfrühten Abschluß: „,Das Ergebnis von Rheinland.Pfalz zeigt, daß die Arbeitgeber bereit sind, sich die $\mathrm{Ab}$ wehr einer qualitativen Forderung etwas kosten zu lassen: eine 11,5\%ige Lohnerhöhung wird um eine Vorweganhebung um 5 \% und die Tarifierung vermögenswirksamer Leistungen ergänzt. Die beiden letzten Zugeständnisse sollen die Forderung nach betriebsnaher Tarifpolitik unterlaufen.".... ,Der Abschluß in RheinlandPfalz führt dazu, daß die A rbeitgeber in Hessen erklären, sie würden auf dieser Basis die Einkommen anheben, auch wenn kein Vertrag in Hessen zustandekäme. Die Betriebsräte der meisten Betriebe, für die Firmentarifverträge abgeschlossen werden sollten, setzen sich daraufhin von ihrer ursprünglichen Forderung ab und melden dem Bezirksleiter, die Belegschaften würden nach einer solchen Vorleistung der 
Arbeitgeber nicht mehr streikbereit $\operatorname{sein}^{\text {"6 }}$ (10). Eberhard Schmidt, der wesentliche Vertreter des Konzept der betriebsnahen Tarifpolitik innerhalb der ,express". Redaktion, kommentiert diesen Verlauf: ,Die Arbeitgeber hatten der Gewerkschaft das tarifpolitische Konzept abgekauft mit aukerordentlichen materiellen Zugeständnissen, nämlich Lohnerhöhungen, die zu den höchsten der Nachkriegszeit zählten" (11).

Die Forderung nach betriebsnaher Tarifpolitik war zunächst innerhalb des IG-Chemie Gewerkschaftsapparats durchzusetzen, weil sich die Gewerkschaftsleitung auf diese Weise eine Einschränkung der Macht der Betriebsräte der Großbetriebe erhoffte. Was sonst durch diese nach der Tarifrunde noch herausgeholt wurde, sollte nun schon innerhalb der Tarifrunde gewerkschaftlich erkämpft und abgesichert werden. Für die Arbeiter der Großbetriebe handelte es sich demanch nicht um eine Verbesserung ihres Lohnes, um die sie hätten kämpfen sollen, sondern urn eine Veränderung des Verhandlungsmodus des Lohns und natürlich seine tarifiche Absicherung. Hier allerdings war wichtig, daß die Chemiearbeiter aufgrund der vergleichsweise guten Situation der Chemieindustrie in der Krise noch nicht (im Unterschied zum Metallbereich) die Erfahrung massiver Streichung übertariflicher Leistungen gemacht hatten. Wie sollte also eine wirkliche Mobilisierung der Arbeiter für diese Forderung stattfinden? Der Strategie des Kapitals war man in diesem Fall hilflos ausgeliefert. Es bleibt dabei zu fragen, wieweit die Forderung überhaupt eine massenhafte Forderung der Arbeiter war, und nicht wesentlich auf Teile des Ge. werkschaftsapparats und der unteren Kader, der Vertrauensleute und der Betriebsräte einiger Betriebe beschrönkt blieb.

b) Betriebsnahe Tarifpolitik als Mobilisierungsstrategie der Gewerkschaftsfïh. rung

Die Entwicklung in der IG.Chemie zeigt auch, daß es durchaus Bedingungen geben kann, unter denen der Gewerkschaftsapparat bereit ist, eine Politik betriebsnaher Verträge durchsetzen zu wollen. Sie verweist auf die Cenese dieser Konzeption in der IG-Metall und ihre Propagierung auch durch Teile des Gewerkschaftsapparats.

Der Ausgangspunkt der Diskussion um die betriebsnahe Tarifpolitik in der IG-Metall zu Ende der 50er Jahre war die Tatsache, daß im Verlauf prosperierender Kapitalakkumulation es den (in der Regel rechten) Betriebsräten möglich war, betriebsinterne Abschlüsse zu erzielen, die weit über den tariflichen Abschlüsen lagen und die sowohl die Stellung dieser Betriebsräte festigten als auch die Belegschaften ,befriedigten ${ }^{66}$ und in ,Apathie ${ }^{66}$ hielten. Das Konzept wurde also ausgearbeitet, um die Belegschaften zu mobilisieren, sie in die betrieblichen Verhandhungen mit einzubeziehen (12), die Betriebsräte zu kontrollieren. Bei den Arbeitern sollte das Be-

10) K. Schacht/L. Unterseher, Das Tarifverhandlungssystem in der $\mathrm{BRD}$, in: Meißner/Unterseher (Hrsg.), Verteilungskampf und Stabilitätspolitik, Stuttgart 1972, S. 211

11) E. Schmidt, Zur Strategie der betriebsnahen Tarifpolitik, in: Kritisches Jahrbuch Gewerkschaften und Klassenkampf 1972, (herausgegeben von O. Jacobi, W. Müller-Jentsch, E. Schmidi) Frankfurt a. M. 1972

12) Vgl. dazu auch die Diplomałbeit von D. Pleiffer/R. Krusche, Das Verhälnis von betrieblichem und zentralem ökonomischen Kampf als Problem der Gewerkschaftsbewegung, Diplomarbeit FU-Berlin 1972, unveröff. Manuskript 
wußtsein von der Notwendigkeit der gewerkschaftlichen Organisierung wachgehalten werden: Es ,besteht die Gefahr, daß durch eine Zentralisierung der Lohn- und Tarifpolitik das gewerkschaftliche Leben in den Bezirken und Verwaltungsstellen erstarrt. Das Interesse und die Anteilnahme der Mitglieder werden zwangsläufig oder können geringer werden und das Wissen um den Zusammenhang zwischen gewerkschaftlicher Aktivität und Kraft auf der einen Seite und der Lohn- und Gehaltshöhe auf der anderen könnte dadurch leicht in Vergessenheit geraten" (13), schreibt Fritz Salm im Jahr 1958.

Das Konzept, das von der IG-Metall durchaus auch zu Beginn der 60er Jahre offiziell bei FORD durchzusetzen versucht wurde, hat demnach seinen Ursprung keineswegs in einem Konflk $\mathfrak{z}$ zwischen ,Gewerkschaftsapparat und Gewerkschaftsbasis", sondern in einer Phase prosperierender Kapitalakkumulation, in der die Notwendigkeit iberbetrieblicher gewerkschaftlicher Organisierung angesichts der Lohnzugeständnisse auf betriebiicher Ebene in Vergessenheit zu geraten drohte (14). Die dariber vermittelte Schwächung der Gesamtorganisation ist auch das wesentliche Motiv zur Propagierung der betriebsnahen Tarifpolitik in der IG-Chemie. Ist es zwar in beiden Fällen die Linke, die diese Strategie vorschlägt und durchzusetzen versucht, so darf dies doch nicht den Blick dafür verstellen, daß es wesentich um die Sicherung des gewerkschaftlichen Verhandlungsmonopols geht, um die Einschränkung des betriebiichen Manipulationsspielraums des Kapitals und die Kontrolle der Betriebsräte.

Das Konzept der betriebsnahen Tarifpolitik selbst entspringt dem grundsätzlichen Problem, daß durch die Durchsetzung von Einheitslöhnen innerhalb der Industriezweige, die Konkurrenz unter den Arbeitern selbst nicht aufgehoben ist. Der Lohn als Preis der Arbeit unterliegt den Regelungsmechanismen der Konkurrenz und die Bewegung der Arbeitskräfte innerhalb und zwischen den Branchen, die Abund Zuwanderung ist reguliert über die differierenden Preise der Ware Arbeitskraft zwischen und innerhalb der Branchen. Die Gesetze der Preisbildung der Ware Ar-

13) zitiert bei E. Schmidt, a. a. O., S. 148/49;

Schachi/Unterseher, Das Tarifverhandlungssystem der BRD, a. a. O., S. 91-93: „Das uberbetriebliche Verhandiungssystem hat jedoch für die betriebliche Ebene gravierende Folgeprobleme ... mit steigendem Zentralisierungsgrad der Lohnverhandlung (steigt) die Driftrate... Diese Entwicklung ist für die Arbeitgeber von Vorteil: sie können durch übertarifliche Lohnteile und Sozialleistungen die Arbeitnehmerloyalität zu ihren Gunsten verschieben, die Legitimationsbasis der Gewerkschaften schwächen und - durch größere Differenzierung der Einkommen - die Arbeitnehmer hierarchisieren, wodurch das Interesse an der kollektiven Lohnaushandlung sinkt und einer solidarisierenden Nivellierungspolitik der Gewerkschaften entgegengewirkt wird. Zugleich erhöht sich mit der Existenz einer übertariflichen, Manipuliermasse' die konjunkturpolitische Flexibilität des Managements. ${ }^{6}$ Die Verfasser weisen darauf hin, daß der Effekt durch die Doppelung der Arbeitnehmervertretung in Gewerkschaft und Betriebsrat noch verstärkt werden.

14) Die Phase ist gekennzeichnet durch regelmäßig steigende Tariflöhne, Erfolge in der gewerkschaftlichen Politik der Arbeitszeitverkürzung, großer Verhandlungsspielraum der Betriebsräte, hohe Lohndrift, Erfolge der Verhandlungspolitik auf Betriebsebene Betriebsrat - und auf gesamtgeseilschaftlicher Ebene - Gewerkschaft - . Die Notwendigkeit der Gewerkschaft als Kampforganisation gerät hier umso eher aus dem Blickfeld, je weniger die Waffe des Streiks in den Tarifauseinandersetzungen angewandt wird. In dieser Zeit fallt auch der gewerkschaftliche Organisationsgrad. 
beitskraft können durch die gewerkschaftliche Aktion nicht grundsätzlich aufgehoben werden, als überbetrieblich agierende Organisation hat die Gewerkschaft Einfluß auf den Wert der Ware Arbeitskraft als Schwankungszentrum der Preise. Sie handelt den Tariflohn als Minimalpreis der Arbeitskraft aus, der Preis der einzelnen Arbeitskraft ist notwendig davon verschieden, auf ihn nimmt sowohl die unterschiedliche Nachfrage nach Arbeitskraft unterschiedlicher Qualifikation als auch die unterschiedliche Nachfrage der Betriebe überhaupt nach Arbeitskräften Einfluß. Ist demnach das gewerkschaftliche Verhandlungssystem in der BRD (im Unterschied zu dem in den USA etwa) auf die Aushandlung von Löhnen für ganze Industriezweige gerichtet, so entsteht notwendig unter Bedingungen der Prosperität, also bei allgemeiner Tendenz des Ansteigens der Löhne, der Schein, als werde der Arbeitslohn durch die günstige Stellung des einzelnen Arbeiters, einer bestimmten Arbeiterschicht, der Arbeiter bestimmter Betriebe innerhalb der Konkurrenz mit dem Kapital und nicht durch die gewerkschaftliche Organisation als der umfassenden Vereinigung der Lohnarbeiter reguliert. Dabei wird die Tatsache verdeckt, daß auch dieser besonders günstige Lohn sich erst auf Basis des von der Gewerkschaft als umfassender Organisation ausgehandelten Minimallohns erhebt.

Wird demnach unter solchen Bedingungen vom Gewerkschaftsapparat eine Kontrolle der betrieblichen Lohnbildung angestrebt, so muß dies nicht heißen, daß damit die Gewerkschaft als politisch bewußte Klassenorganisation angestrebt wird, gegenüber der Vereinzelung der Betriebe, der einzelnen Arbeiter, der Arbeiterschichten in der Konkurrenz.

Demnach handelt es sich auch bei der Abweichung der Preise der Arbeit, die innerhalb einzelner Betriebe und für einzelne Arbeiterschichten gezahlt werden, von den zentral ausgehandelten Löhnen nicht einfach nur um eine vom Einzeikapital quasi willkürlich zu handhabende Manipulationsmasse, welche allein dem Zweck der Disziplinierung der Arbeitskraft dient - in den express Thesen heißt es, durch betriebsnahe Tarifpolitik solle ,die betriebliche Sozialpolitik als wichtigstes Disziplinierungsinstrument der Unternehmer" ausgeschaltet werden - sondern zunächst um eine ökonomische, $d . h$. über die Zwangsgesetze der Konkurrenz vermittelte Kategorie der wirklichen Verhältnisse, die natürlich vom Einzelkapital genutzt wird, um die Arbeiter wiederum im gesellschaftlichen Zustand der Konkurrenz zu halten. Diese Möglichkeit ist wiederum dem Kapital nur solange an die Hand gegeben, wie seine Konjunktur, (die bei nichtentwickeltem Druck einer industriellen Reservearmee besonders den qualifizierten Arbeitern eine vorübergehend starke Position innerhalb der Konkurrenz mit dem Kapital verschafft) eine allgemeine Besserung des Lebensniveaus der Arbeiterklasse erlaubt. Es ist bekannt, daß in Phasen krisenhafter Entwicklung die Tendenz sich herausbildet, daß die sogenannte ,Lohndrift ${ }^{6}$ verschwindet, die Effektivlöhne sogar unter die Tariflöhne fallen (wie z. B. in der Krise 1966/67).

In diesem Zusammenhang kann nicht die Frage entwickelt werden, welche Politik die Gewerkschaft tatsächlich hätte machen können und machen müssen, um dem in der Prosperitätsphase gerade bei den Facharbeitern (der traditionellen Basis der IG-Metall) entstehenden Illusion, sie könnten als einzelne oder die Betriebsbelegschaften könnten ais einzelne mit dem Kapital konkurrieren, entgegenzuwirken. 
Wichtig ist, daß dieser Schein der Konkurrenz, bestätigt durch die wirklichen Verhältnisse in Phasen der Prosperität, vom Kapital selbst infrage gestellt wird, wenn seine Akkumulationsschwierigkeiten sich entwickeln und verschärfen.

Die Zahlung hoher Löhne ist ein durchaus ungewöhnliches „Disziplinierungsmittel“s, an dem die Arbeiter kaum ihren antagonistischen Widerspruch zur kapitalistischen Gesellschaft erfahren werden. Hängt dem Arbeiter ,die goldene Kette ${ }^{66}$ um den Hals, so wird ihm auch die Herrschaft des Kapitals weniger bekämpfenswert erscheinen. Diese Herrschaft des Kapitals, die „Disziplinierung der Arbeiterklasse" kann dann zum Gegenstand der Erfahrung des Klassenwiderspruchs werden, wenn sie eben ihren wirklichen Inhalt hervorkehrt, nämlich jene Zugeständnisse zurückgenommen und der materielle Widerspruch zwischen den Lebensbedürfnissen der Lohnabhängigen und den Notwendigkeiten der Kapitalakkumulation sichtbar wird. Die normalen Mittel der Disziplinierung sind für das Kapital eben nicht hohe Löhne innerhalb des Betriebes, sondern die industrielle Reservearmee vor der Tür, die die Konkurrenz unter den Arbeitern verschärft: Jene Konkurrenz, die sie zwingt, sich mit niedrigen Löhnen zufrieden zu geben, um überhaupt eine Arbeitsstelle zu finden und die sie gleichermaßen zwingt, die Arbeitsleistung im Produktionsprozeß übermäßig zu steigern, um auf ihren Lohn zu kommen und um den Arbeitsplatz zu behalten.

Ging es also um die Wende der 50er Jahre bei der Entwicklung des Konzepts betriebsnaher Tarifpolitik innerhalb der IG-Metall darum, einen Weg zu finden, wie die Organisation den Arbeitern ihre Notwendigkeit entgegen den Erfahrungen, als einzelne mit dem Kapital konkurrieren zu können, klar machen sollte (übrigens ohne dabei - mit Ausnahme vielleicht von Ford, wo es wesentlich auch um Arbeitsbedingungen ging - inhaltliche Alternativen ihrer Politik angeben zu können), so handelte es sich, als das Konzept nach der Krise 1967 von unteren Gewerkschaftskadern, vor allem auch von Betriebsräten (und nicht einfach nur Vertrauensleuten) wieder aufgegriffen wurde, um etwas anderes.

c) Betriebsnahe Tarifpolitik als Abwehr- und Legitimationsstrategie Ist die Krise 1966/67 einerseits Anlaß für die vollendete Hinwendung der Gewerkschaftsführung zur bürgerlichen Politik, so bildet sie auf der anderen Seite für die Arbeiter die erste einschneidende Erfahrung ihrer Existenz als Klasse gegenüber dem Kapital nach der langen Prosperitätsphase. Es zeigt sich jetzt nämlich, wenn auch unterschiedlich in den einzelnen Produktionszweigen, daß die aufgrund ausnahmsweis günstiger Konkurrenzposition gewonnene Stellung gegenüber dem Kapital eine durchaus schwankende und unsichere ist. Das Kapital ist gerade aufgrund der Tatsache, daß die Lebensbedingungen der Arbeiter nicht durch eine einheitliche kampffähige Organisation abgesichert sind, sondern durch die zufällige Konkurrenzposition der Einzelbetriebe bestimmt schienen, in der Lage, Lohnkürzungen bis zu $40 \%$ und steigenden Druck auf das Arbeitstempo vorzunehmen, ohne daß ein gewerkschaftlich organisierter. Abwehrkampf dagegen geführt werden könnte. Es wird wieder die Erfahrung der Gefahr der Arbeitslosigkeit gemacht. Die Situation ermöglicht die Erkenntnis, daß das Schicksal des einzelnen Arbeiters weniger durch seine Leistung als Individuum, denn durch die Bewegung des Kapitals bestimmt ist, Ansätze erneuter Erfahrung des Klassengegensatzes werden gemacht. Zwar kann die 
Gewerkschaft gegenüber den Arbeitern jetzt mit Genugtun darauf hinweisen, daß sie ja schon immer die Notwendigkeit der gewerkschaftlichen Organisation betont habe, die Wirtschaftskrise sei das beste Beispiel, daß ohne Gewerkschaften nicht auszukommen sei, doch dieser Hinweis auf die Notwendigkeit der solidarischen Organisation steht im Widerspruch zur der - mit dem Eintritt in die Konzertierte Aktion - vorerst vollendeten Integration in die Politik des bürgerlichen Staates.

Sehen wir uns nun an, unter welchen Vorzeichen die Forderung nach betriebsnaher Tarifpolitik - jetzt als Forderung aus den Betrieben - entwickelt wird:

Zum einen geht es gerade den Betriebsräten, welche die Erfahrung der man. gelnden Absicherung der von ihnen ausgehandelten Löhne 1967 machen, un das Bestreben, ihre Position gegenüber dem Kapital, aber auch in bezug duf die Beleg. schaft, eben durch die Möglichkeit des Einsatzes gewerkschaftichen Drucks, gewerkschaftlich-tariflicher Absicherung der Löhne zu stärken. 1967 ,schei sert die Betriebsrätepolitik, deren ,Leistungen ${ }^{6}$ der autonomen Kosienkalkulation des Ma* nagements zum Opfer fallen. Die Folge war im Organisationsbereich der IG.Metall, in dem besonders viele Kürzungen während der Rezession stattfanden, daß sich die betrieblichen Funktionäre" (im Metallbereich sind die Betriebsräte eben zumeist IG-Metallvertreter) ,wieder stärker an der Gewerkschaft orientierten und daß sie eine ,betriebsnahe Tarifpolitik forderten, die einmal zu einer tariflichen Absicherung der betrieblichen Sonderzulagen führt und ihnen zum anderen die Partizipations- und Entscheidungschancen im tariflichen Bereich sichert" (15).

Dabei kann, muß aber nicht notwendig die Forderung nach betriebsnaher Tarifpolitik diejenige von klassenbewußten Betriebsräten und Vertrauensleuten sein, muß nicht die Einsicht in die Notwendigkeit der Entwicklung von Klassenbewußtsein und selbständiger Organisationsfähigkeit und Kampffähigkei der Arbeiter auf der Ebene zunächst des Betriebs beinhalten. Sie kann durchaus auch, wie Schacht/Unterseher annehmen, einer ,Interessenlage ${ }^{66}$ entspringen, welche auf eine „Sicherung der Legitimationsbasis" der betrieblichen Funktionäre aus ist: denn diese Legitimationsbasis ist eben nur solange gesichert, -- insbesondere angesichts der beschränkten gewerkschaftlichen Zielsetzungen -, wie es den betrieblichen Gewerkschaftsfunktionären, zunächst den Betriebsräten (die Stellung der Vertrauensleute ist so oder so schwach aufgrund ihrer mangelnden Möglichkeit, verbindliche Verhandlungen mit dem Kapital zu führen), gelingt, eiwas für die Belegschaft, herauszuholen', sei es mit, sei es ohne die Gewerkschaft als überbetriebliche Organisation. Die Forderung kann also durchaus dem Wunsch entspringen, die alte Vertreterpolitik mit neuen Mitteln durchzusetzen. In ihr spiegelt sich die Einschränkung des Verhandlungsspielraums der Betriebsräte angesichts der Krise. Die Senkung der Löhne in der Krise erscheint dabei primär eben als Resultat mangelnder institutioneller Machtmittel, nicht aber als Resultat des objektiven Interessengegensatzes und

15) Schacht/Unterseher, a. a. O., S. 95;

Hier sei übrigens nur erwähnt, daß es uns kein Zufall zu sein scheint, daßs nach einer bisher unveröffentlichten Studie von Teschner/Mosler $u$. a. über Lohndifferenzierung bei vielen Betriebsräten der IG-Metall, nicht aber bei denen der Gewerkschaft Textil-Beklejdung zu finden ist. Kein Zufall deshalb, weil gerade die schon immer schwierige Situation in der Textilindustrie der Vorstellung, auf einzelbetrieblicher Ebene dem Kapital Zugeständnisse abzwingen zu können, die Basis raubt. 
des Entwicklungsgrads der Kampfrähigkeit der Klasse. Dabei mögen bei Teilen der Betriebsräte die Septemberstreiks durchaus die Forderung noch forciert haben. Und zwar nicht vermirtelt über die Vorstellung, die Kampffahigkeit der Klasse wäre stärker gewesen, wenn die Streiks im Rahmen einer betriebsnahen gewerkschaftlichen Tanfpolitik stattgefunden hätten, sondern vermittelt über die zwiespälțge Position, in welche betriebliche Gewerkschaftsfunktionäre bei nicht gewerkschaf. fich organisierten Streiks notwendig geraten, sofem solche Streiks gleichzeitig Kritik der yorgefundenen Gewerkscheftspolitik implizieren.

Ein Eeispiel in dieser Richtung bildet die nevere Geschichte der Forderung nach betriebsnaher Tarifpolitik bei FORD: Teile des Betriebsrats und der Ver. ravenskörper samt seiner Leitung (Kuckelkorn), die eine durchaus bekannte frag-

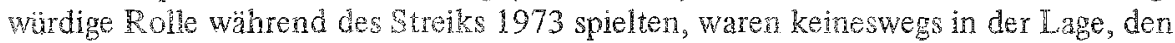
spontanen Streik zu organisieren und in seiner Kamprkraft zu stärken, distanzierten sich sogar durch thre praktische Politik vom Streik und forderten sowohl vor als auch nach tem Strik betriebsnahe Taripolitik. In dem Film, Wie man Löhne mach $\hat{\imath}^{66}$ (vorgetragen von $\mathbb{K}$ uckelkorn) wird deutlich, dak die Forderang selbst die Funktion der Legitimation einer folschen Politik und der Verdrängurge eines mögli. chen LeFraprozesses hat. Statt auf der dem Streik folgenden Vertravenskörpersit. zung den Streik und die Ursachen des eigenen Versagens zu untersuchen, wird zum soundsovielten Mal die betriebsnahe Tarifpolitik gefordert. Das heirt aber, man folgt der Vorstellung, als sei die harte Auseinandersetzung bei Ford zwischen Arbei. tern und Kapital vermeidbar gewesen, wenn nur den betrieblichen Funktionären die richtigen institutionellen Mittel in der. Hand gewesen wären, mir Erfolg zu venhandeln. Angestrebtes Ziel scheint dabei weniger die effektivere Fuhnung des Streiks als seine Vermeidung gewesen zus sein.

In diese Richtung läuft z. B. auch die Argumentation von Schacht/Unterseher, wenngleich sich ihnen das Problem weniger als Frage der Legitimation betrieblicher Gewerkschaftsfunktionäre demn als Problem der störungsfreien Durchsetzung einer an der ,Verstetigung der Konjunktur" orientierten gewerkschaftlichen Tarifpolitik bei gleichzeitiger Erhaltung des gewerkschaftlichen Verhandlungspotentials stellt. Dabei gehen sie, was den Leser überrascht, davon aus, die sozialdemokratische Wirtschaftspolitik seit 1967 zeige bereits erste Anzeichen der Moglichkeit einer Versteíigung der Konjunktur durch die Staatseinwirkung, wobei für sie Verstetigung identisch z $\mathrm{k}$ sein scheint rit kontinuierlichem Wirtschaftswachstum. Eine solche Politik sei won den Gewerkschaften zu unterstïtzen, und zwar durch, ,Verstetigung von Lohnzuwächsen, deren quasi automatische Erwarłbarkeit". Dabei befürchten die Verfasser allerdings, daß "Lohnerhöhungen als relativ problemlose Teilhabe am allgemeinen Fortschritt ${ }^{\text {"6 }}$ die Gewerkschaft in die Gefahr bringe, ,ihre Legitimationsbasis zu verlieren". Um einerseits ,betriebliche Verteilungskämpre, die das Gesamtverhandlungssystem sprengen" zu verhindern, andererseits aber die gewerkschaftliche Legitimationsbasis zi erhalten, empfehlen die Autoren, in allerdings etwas umständlichen Umschreibungen, betriebsnahe gewerkschafliche Politik, um die „betriebliche Konfliktregelung gesantwirtschaftlich kalkulierbarer und zugleich reicher an Emanzipationschancen zu machen. Anzustreben sei dabei, daß, qualitative Forderungen" die sich auf die Herrschaft in Betrieb richten, Gegenstand betrieblicher 
Gewerkschaftspolitik werden, während die Lohnerhöhungen sich nach Maßstäben gesamtwirtschaftlicher Rationalität im Sinne der beschriebenen Konjunkturverstetigung richten sollten (16). Die falschen Voraussetzungen einer solchen Gewerkschaftspolitik liegen auf der Hand. Sie reichen von den Illusionen in die Möglichkeit der Verstetigung und Aufrechterhaltung wirtschaftlichen Wachstums durch staatliche Regulierungspolitik bis hin zur Trennung der Herrschaft des Kapitals über den Produktionsprozeß und der Anwendung der Arbeit als institutioneller Form von ihrem Inhalt, der Aneignung von Mehrarbeit.

Auf diesen Fehlern der Analyse selbst beruht aber die Anempfehlung betriebsnaher Tarifpolitik als Mittel der Integration und Unterordnung der Arbeiter unter gewerkschaftlich vermittelte Richtlinien staatlicher Einkommenspolitik (konzertierte Aktion).

Dieses Beispiel sollte nur zeigen, wie fragwürdig es ist, die Verhandlungsform be triebsnahe Tarifpolitik zu einer wesentlichen Forderung autonomer sozialistischer Gewerkschaftspolitik zu erheben, ohne daß die Widerstände, aber auch die möglichen Interessen der Gewerkschaftsführung an einer solchen Politik inhaltlich aufgezeigt würden. Ihre naive Propagierung kann in Zugeständnissen resultieren, welche die Konflikte -zwischen der, Politik des Gewerkschaftsapparats und der Gewerkschaftsbasis ${ }^{6}$ durch Scheinpartizipationen der Basis zu mildern sucht, um gleichzeitig die eingeschlagene inhaltliche Politik umso effektiver durchsetzen zu können. In diesem Zusammenhang wären z. B. die partiellen Zugeständnisse an die Vertrauensleute der IG-Chemie, welche deren Teilnahme an der Tarifpolitik verbessern, in ihrer realen Auswirkung zu untersuchen. Eine erste Einschätzung der Mißerfolge der Verbesserung der Position der Vertrauensleute in der IG-Chemie angesichts einer Tarifrunde findet sich in der Zeitschrift Arbeiterpolitik.

d) Betriebsnahe Tarifpolitik als eine organisatorische Form der Entfaltung der

Kampífähigkeit der Klasse

Auf der anderen Seite kann die Forderung nach betriebsnaher Tarifpolitik durchaus einem Bewußtsein entspringen, welches Entfaltungsmöglichkeiten und organisatorische Formen für die Kampffähigkeit der Klasse sucht. Zum einen deshalb, weil ja in der Tat durch die Trennung zwischen betrieblicher und überbetrieblicher Interessenvertretung in Gewerkschaft und Betriebsrat bei Friedenspflichtbindung des Betriebsrats es nicht möglich ist, das gewerkschaftliche Kampfpotential und die potentielle organisatorische Kraft der Gewerkschaft zur Stärkung der Kampffähigkeit der Lohnarbeiter in der Auseinandersetzung mit dem Einzelkapital einzusetzen, was eire tatsächliche Schwächung bedeutet. Zum anderen liegt es aber auch deshalb nahe, in einer Situation zunehmender Konflikte zwischen zentraler Tarifpolitik der Gewerkschaftsfïhrung und den Bedürfnissen der Arbeiter zunächst betriebsnahe Tarifpolitik zu fordern, weil, wie in den anfänglichen Herleitungen gezeigt, unter der historischen Bedingung des sogenannten ,Basis-Apparat Konflikts der Betrieb zunächst die organisatorische Basis ist, auf der die Arbeiter auch unabhängig von der zentralen Gewerkschaftsorganisation in ihrer Eigenschaft als zusammenfassender Organisation selbständig zu kämpfen in der Lage sind. Gerade angesichts der Konzertierten Aktion entwickelt sich dabei die Vorstellung, die Einkommenspoli-

16) Sämtliche Zitate: Schacht/Unterseher, a. a. 0., S. $114 \mathrm{f}$. 
tik-orientierte Linie des Gewerkschaftsapparats durch betriebliche Kämpfe durchkreuzen zu können. Hinzu kommt noch das Mornent, welches wir im Aufsatz ,Zum Zusammenhang von Kapitalakkumulation, Veränderungen in den Formen der Profitproduktion und der Rolle neuerer Entlohnungsmethoden in der BRD" (PROKLA Nr. 4 und 5) entwickelt haben: Die Tendenz zur Intensivierung der Arbeit, Verschlechterung der Arbeitsbedingungen, die zunächst über die Herrschaft dies Einzelkapitals im Betrieb vermittelt erscheint und je besondere Formen in den einzelnen Betrieben annimmt, so daß der besondere betriebliche Abwehrkampf und die Befähigung der Gewerkschaft bzw. der betrieblichen Gewerkschaftskader, ihn als gewerkschaftlichen auf der Ebene des Einzelbetriebes zu führen, die Forderung nach betriebsnaher Tarifpolitik nahelegt.

Gegenüber diesen realen Problemen der Klassenbewegung, wie sie sich in der Forderung nach betriebsnaher Tarifpolitik widerspiegeln, erscheinen allerdings A Igumentationen, wie sie der KB Hamburg beispielsweise im März 1973 und im Januar 1974 im ,Arbeiterkampf“" entwickelt, leere Abstraktionen (17). Dem schon nahezu traumatischen Verhalten folgend, in allen Aktionen der Gewerkschaftsführungen den unmittelbaren Klassenverrat zu wittern, kommt den Autoren des ,Arbeiterkampfes" die Tatsache, daß Teile des IG-Chemie Gewerkschaftsapparats um die Wende der 70er Jahre eine betriebsnahe Tarifpolitik forderten und durchzusetzen versuchten, gerade recht, um diese auch von der linken Gewerkschaftsbasis diskutierte Forderung als Werk einer schlimmen Allianz von Gewerkschaftsführung und Kapitalistenklasse zu entlarven: ,Diese (die betriebsnahe Tarifpolitik) paßt sich nämlich nahtlos in das kapitalistische Wirtschafts- und Gesellschaftssystem ein, indem sie jedem Kapitalisten nur , das zumutet, was er leisten kann'. Wenn eine Tarifpolitik hundertprozentig systemkonform ist, so ist es die ,betriebsnahe Tarifpolitik' “. Deshalb bedeutet betriebsnahe Tarifpolitik nicht ,Stärkung, sondern Zerschlagung gewerkschaftlicher Solidarität ${ }^{\text {". }}$. Und an anderer Stelle heißt es: ,Die Gewerkschaftsführung (hat) in Wirklichkeit bloß eine endlose Aufsplitterung von Lohnverhandlungen ins Auge gefaßt ... Betriebsnahe Tarifpolitik ${ }^{6}$ ist nichts weiter als ein Versuch der Kapitalisten, die Arbeiterklasse ,klein ${ }^{6} \mathrm{zu}$ halten und breite Lohnkämpfe zu verhindern." Wie dies mit dem Faktum des Widerstands des Chemie-Kapitals gegen den Versuch der IG-Chemie zur Praktizierung betriebsnaher Tá rifpolitik in Übereinstimmung kommen soll, wird dem Leser nicht vermittelt. Es geht dann weiter: ,Betriebe wie Merck-Darmstadt oder Clouth-Köln, die eine gewisse Kampfstärke behaupten konnten, ,müssen“ im Zuge der Durchsetzung ,betriebsnaher Tarifpolitik ${ }^{6}$ ebenfalls als Anführer von Streikbewegungen ausgeschaltet werden." Demgegenüber muß verwundern, daß gerade der fortschrittliche Vertrauenskörper von Merck/Darmstadt einer der Protagonisten der Forderung nach betriebsnaher Tarifpolitik in der IG-Chemie war. Diese Tatsache wird damit begründet, daß der ursprüngliche Antrag der Merck-Vertrauensleute auf dem Gewerkschaftstag verfälscht wurde. Weshalb er jedoch gestellt wurde, wird nicht geklärt. Auf der anderen Seite kommen die Autoren der Artikel nicht umhin festzustellen, daß die Klöckner-Hütte Bremen eine eigene Tarifkommission hat (da es im Tarifbezirk Unterweser keinen weiteren Stahlbetrieb gibt), die von einkommenspolitischer Linie des

17) Die folgenden Zitate aus, Arbeiterkampfo, März 1973 (Nr. 28) und Januar 1974 (Nr. 38) 
Vorstandes abweichende Forderungen stellt. Die Tatsache der Nichtbeachtung der Forderungen durch den Vorstand in der Tarifauseinandersetzung 1972/73 legen die Autoren nun wieder als Beleg dafür aus, daß die Gewerkschaftsführung doch macht, was sie will, eine betriebsnahe Tarifpolitik könne also den Arbeitern nicht gegen den Leviathan von Gewerkschaftsapparat helfen. Linke Gewerkschaftler, die betriebsnahe Tarifpolitik fordem, erscheinen daher dem Leser als arme, unbemittelte oder gar unbewußte Erfüllungsgehilfen des Klassenverrats. Indem die Artikel an keine? Stelle die wirklichen Probleme der Klassenbewegung herausarbeiten, die der gewerkschafilichen Diskussion um die betriebsnahe Torifpolitik zugrundeliegen, verheddern sich die Autoren permanent in Widerspriche und Verdrehungen der wirklichen Probleme.

Gehen wir zurück zu dem Punkt, wo wir von der mit der Krise 1967 veränderten Situation sprachen und aus ihr die Entwicklung der Forderung nach betriebsnaher Tarifpolitik bei betrieblichen Gewerkschaftsfunk tionären abzuleiten suchten. Versuchen wir nun, diesen Unterschied noch einmal genauer zu fassen, und zwar in bezug auf die Probleme des Verhältnisses von Konkurrenz und Klasseneinheit, vermittelt uber die gewerkschaftliche Organisation. Im Unterschied zu der Phase der Entwicklung, wo die Gewerkschaftsführung der IG-Metall teils selbst das Konzept der betriebsnahen Tarifpolitik propagierte, stellt sich das wesentliche Problem der Saärkung der Kampffähigkeit der Lohnarbeiter gegenuber dem Kapital heute zunehmend in der Form dar, daß der Druck einer sich entwickelnden industriellen Reservearmee, Entlassungen, Unsicherheit des Arbeitsplatzes auf der einen, die an staatlicher Wirtschaftsregulierung keynesanischer Prägung orientierte Politik der Gewerkschaftsfihhungen andererseits die Entwicklung der Klassensolidarität hindern. Es geht weniger darum, die Illusion aufzuheben, der einzelne könne zu seinem besten als einzelner mit dem Kapital konkurrieren, sondern die gewerkschaftliche Organisation hat der Ausnutzung der Konkurrenz der Arbeiter untereinander als Mittel der Lohnsenkung und Abpressung von Mehrarbeit entgegenzuwirken. Diese Aufgabe trifft auf einen realen Gewerkschaftszustand, in welchem große Teile der Gewerkschaftsgremien den Widerstand gegen die Politik des Kapitals deshalb nicht aufzunehmen bereit sind, weil sie sich von einer Unterstützung der staatlichen Wirtschaftspolitik durch lohnpolitische Zurickhaltung eine dauerhafte Verbesserung und Sicherung der Lage der Arbeiter versprechen, tatsächliche Verschlechterungen als voribergehende kleinere Utbel hinzunehmen bereit sind. Eine ,Mobilisierung 'der Basis muß also, anders als zu Beginn der 60er Jahre, dem Interesse und den Inhalten der offiziellen Gewerkschaftspolitik geradewegs zuwiderlaufen. Sowohl die Propagierung des Konzepts zu Beginn der 60er Jahre wie seine Ablehnung zu Beginn der 70 er Jahre durch Teile des Gewerkschaftsapparats oberhalb der Betriebe spiegelt jedoch die reformistische Ideologie und Struktur der Organisation, wie wir sie zu Beginn der Thesen dargestellt haben. Kern des gewerkschaftlichen Reformismus ist eben die Vorstellung, es bedürfe nur der Organisation, um dem Kapital die Sicherung der Existenzbedingungen der Arbeiter und einen Anteil am wachsenden gesellschaftlichen Reichtum, (von dem natürlich seine durch staatliche Manipulation herstellbare Stetigkeit vorausgesetzt wird) abzuzwingen. Schien die Organisation zu Beginn der 60 er Jahre durch das mangelnde Interesse an der Organisation aufgrund 
betrieblicher Zugeständnisse des Kapitals an die Belegschaften, vermittelt ibber die Betriebsräte, gefährdet, so erscheint sie dem Gewerkschaftsapparat gegenwärtig eher gefährdet durch die selbständigen Kampfaktionen der Belegschaften, die als Gefährdung der Gewerkschaftseinheit denunziert werden. Eine solche Politik muB aber bewiiken, daß resignative Tendenzen innerhalb der Arbeiterklasse gestärkt werón. denn die Erfahrung, durch welche die Arbeiter vom Kapital ,mobilisiert werden, verweisí sie auf die Notwendigkeit der Aufhebung der Konkurrenz, aber eben zu dem inhalthichen $Z$ weck, sich gegen die Tendenzen der Herabsetzung der Lebensoedingungen durch Kämpfe zur Wehr setzen zu können. Die Erfahrung zeigr auch, dies haben wir in dem Aufsatz „Neue Momente in der Klassenbewegung 1973 in der Metallindustrie" (18) darzustellen versucht, daß für den nur betrieblichen Abwehrkampf Grenzen in der Organisation des Kapitals als Klasse und seiner Strategie gesetzt sind.

Eine Unterordnung der Arbeiter unter die gegenwärtige Gewerkschafisolitik kann allein in einer Verschärfung der Konkurrenz der Arbeiter untereinander resul. tiewen. Sichert nicht die Gewerkschaftsorganisation das Lohnniveau ab, bietet sie keine Perspektive der Organisations- und Kampfähigkeit gegenibber dem Kapital, so sind die Arbeiter entweder auf selbständige Abwehrkämpfe oder auf die Verschärfung der Konkurrenz untereinander verwiesen: Steigerung der Arbeitslestung, Hinnahme niedriger Löhne, beides in der Hoffnung, so noch, und wenn atich nut individuell, Lebensniveau und Arbeitsplatz absichem zu können.

Müssen sich also auf der einen Seite notwendig, angesichts des Zuztands der Gewerkschaftspolitik, Klassenauseinandersetzungen auf betrieblicher Ebene und auch ohne gewerkschaftliche Unterstützung und Legitimierung entíalten, so kann doch eine sozialistische Gewerkschaftsstrategie nicht in ihrem Reswliat darauf hin ausiaufen wollen, diesen Zustand der betrieblich isolierten Auseinandersetzwng mit dem Kapital noch institutionell absichern zu wollen; zumal er sowohl eive Schwächung der Kampffähigkeit bedeuten kann als auch einen Weraicht auf der Versuch (19), die Politik des Gewerkschaftsapparats insgesamt unter Druck zu setzen. Geht es doch um das Problem, wie die Betriebe, die in den spontanen Kämpten eine große Kampfiraft entwickelt haben, für die Veränderung der Cewerkschaftspolitik und fur die Auseinandersetzungen mit dem Kapital zu einex produk iven Kraft werden können. Wenngleich daher die Konzeption der , express" ${ }^{64}$ Redaktion eine wichtige Funktion haben kann, insofern sie auf die betriebsspezifischen Entloh. nungsmethoden, Fragen der Arbeitssicherheit, der Absicherung betrieblich erreichter Effektivlöhne einzugehen vermag, ist doch anzuzweifeln, daß diese Konzeption die oben skizzierce Problematik zu erfassen in der Lage ist. Denn die öfmungsklazseln verlugern ja gerade die betriebsspezifischen Auseinandersetzungen in die Zeit nach dern regionalen Tarifabschluß und verhindern so geradezu eine solche produktive Funktion gegenüber der gewerkschaftlichen Tarifpolitik, wie wir sie oben angedeutet haben. Sie können so insofern eine demobilisierende Funktion gegenüber den einzelnen Betrieben haben, als in der Hoffnung auf die nachgelagerten betrieblichen Verhandlungen die Auseinandersetzung nicht mehr mit aller Kraft auf der

18) In Probleme des Klassenkampfs, Nr. 10/1973, S. 35-39

19) vgl, ebd. 
regionalen Ebene geführt werden könnte.

Dabei handeli es sich bei der Frage der Ausnutzung der Kampffähigkeit der Avantgardebetriebe für eine Veränderung der Politik der Gesamtorganisation gegenwärtig wesentlich darum, wie überhaupt den Tendenzen der Lohnsenkung und Arbeitsintensivierung angesichts drohender Entlassungen oder drohender Kurzarbeit Widerstand entgegenzusetzen ist. Gerade Beispiele wie die Verhandlungen bei VW in diesem $₫ a h r-V W$ hat einen betriebsnahen Firmentarifvertrag - zeigen, daß die betriebsnahe Verhandlung bei schlechter Gewinnsituation des Betriebs keineswegs ein Fortschritt ist. Hier zeigt sich, daß das reale Problem eben nicht darin besteht, eine vom Betriebsrat ausgehandelte Lohnerhöhung noch gewerkschaftlich abzusichern oder gewerkschaftlich statt durch den Betriebsrat auszuhandeln, sondern überhaupt eine Lohnerhöhung durchzusetzen, wobei es vor allem darauf ankäme, daß die Kampfkraft der Gewerkschaft unabhängig ist von der Gewinnsituation einzelner Kapitale. Denn diese Verwertungssituation selbst ändert sich um keinen Deut, wenn die Gewerkschaft statt des Betriebsrats die Löhne aushandelt.

Der hier schon angedeutete ahistorische Charakter dieser Konzeption von betriebsnaher Tarifpolitik wird also dann besonders deutlich, wenn man die historisch entwickelten Probleme der Arbeiterklasse Anfang der 70er Jahre untersucht. Weder der durch hohe Inflationsraten und staatliche Einkommenspolitik vermittelte Druck auf den Reallohn der Lohnabhängigen (dies im Verein mit drohender Arbeitslosigkeit) noch die als Folge stagnierender Kapitalakkumulation erfolgten Freisetzungen von Arbeitskraft finden (politisch) in diesem, Modell' eine adäquate Antwort. Wir haben hier das Modell als Modell sozialistischer Gewerkschaftspolitik kritisiert, das den Weg einer richtigen Strategie zur Entwicklung von Klassenbewußtsein und Kampfstärke der Arbeiterklasse aufzeigen soll. Wie allerdings gewerkschaftiiche Tarifpolitik angesichts der dargestellten Probleme (Gewerkschaft - Betriebsrat; Verhältnis Belegschaft - Einzelkapital; innergewerkschaftliche Demokratie - staatliche Einkommenspolitik; Verhältnis Lohn - Arbeitsbedingungen) auszusehen hätte, ist hier nur als Problem angerissen, hätte allerdings Gegenstand genaverer Analysen an konkreten Fällen und Problemen zu sein.

\section{Zusammenfassung:}

Es lassen sich also mindestens drei verschiedne Strömungen unterscheiden, die von ihrer innergewerkschaftlichen Interessenstruktur her alle für die betriebsnahe Tarifpolitik eintreten könnten:

1. Betriebsräte, die die tarifvertragliche Absicherung der betrieblichen Verhandlungsergebnisse zwecks besserer Legitimation gegenüber den Kollegen benutzen und die ihre Macht gegenüber den Gewerkschaften in Phasen schärferer ökonomischer Konflikte erhalten.

2. Der Gewerkschaftsapparat, so weit er glaubt, durch eine Scheinpartizipation an der Entscheidung des Vorstandes in seiner Tarifpolitik mehr Resonanz, vor allem aber mehr demokratische Legitimation zu erhalten, ohne auch nur um ein Iota die Strukturen der Entscheidungskompetenzen modifizieren zu 
müssen.

3. Die an konsequenter Gewerkschaftspolitik ausgerichteten Linken, die der Machtfülle des Vorstands eine innere Demokratisierung von unten in den Gewerkschaften entgegenzusetzen hoffen. Dies hätte aber zur Konsequenz, Forderungen aufzunehmen wie die Anerkennung der Verhandlungs- und Streikfähigkeit der unteren Gremien (etwa im Falle drohender Einschränkung der Produktion), wie die Anerkennung der Urabstimmung, die Möglichkeit der Wahl und $\mathrm{Abwahl}$ yon Gewerkschaftsvertretern etc.

Ein Kampf um eine betriebsnahe Tarifpolitik im innerorganisatorischen Karussell des Gewerkschaftstages ist eine zu abgehobene Ebene, als daß sich gegenwärtig dafür die Mitglieder mobilisieren ließen - so wichtig eine Umformung der Entscheidungsstruktur für die Entwicklung der Gewerkschaft zur Kampforganisation der Arbeiter auch sein würde. Dem steht dariberhinaus entgegen, daß der Gewerkschaftstag sich gerade aus mindestens diesen drei Strömungen zusammensetż und so - wenn uberhaupt - eine Konzeption betriebsnaher Tarifpolitik beschlossen werden würde, die den äußerst gegensätzlichen Intentionen, gerecht ${ }^{\text {t }}$ werden müßte, sollte sie die Mehrheit erhalten. Das Resultat wäre wahrscheinlich ein äußerst fragwürdiger Kompromiß, bestimmt aber keine Konzeption für die Entwick. lung der Kampfkraft der Arbeiterklasse.

\section{Handungsperspektiven und Handiungsschranken sozialistischer Gewerk- schaftsarbeit}

Es ging hier nicht darum, die von klassenbewußten Gewerkschaftern entwickelten Strategien und Forderungen zur Demokratisierung der Gewerkschaften als illusionäre oder gar falsche Politik darzustellen. Es ging darum, ihre Richtigkeit, aber auch ihren historischen Stellenwert und ihre Schranken aufzuzeigen. Gehen wir, wie anfangs gezeigt, davon aus, daß Klassenauseinandersetzungen, wenn sie zim offenen Klassenkampf werden, vor allem in den Gewerkschaften ein organisatorische Bewegungsform finden müssen, so ist dabei vorausgesetzt, daf der innergewerkschaftliche Willensbildungsprozeß so organisiert sein muß, daß den Arbeitern von einer sozialpartnerschaftlichen Politik des Gewerkschaftsapparats die Gewerkschaft nicht gänzlich als Kampfinstrument aus der Hand geschlagen werden kann. Unabhängig von der konkreten Politik der Gewerkschaftsfuhrung und unternehmerfreundlicher Betriebsfunktionäre sind eben (wie schon oben dargestellt) die Gewerkschaften die Organisation, in welcher die Arbeiter eine Vereinigung zum Zweck der Verteidigung ihrer Lebensinteressen gegenüber dem Kapital gebildet haben. Die verschiedenen Schichten der Arbeiter und auch die unterschiedlichen politischen Richtungen sind in der Gewerkschaftsorganisation der BRD zusammengefaßt. Der Zusammenhang über die einzelnen Betriebe hinaus ist durch die Organisation zunächst gesetzt. Der Verzicht auf den Kampf um die Gewerkschaft als Klassenkampforganisation würde die Arbeiter entmachten, sie in Niederlagen in ihrer Auseinandersetzung mit dem Kapital treiben, Niederlagen, die keine Perspektive außer der der Ohnmacht und Resignation offenließen. Allein die Empörung über die Unterdrückung und Ausbeu- 
tung und die resignative Enttäuschung iber die offizielle Gewerkschaftspolitik schaffen noch kein Klassenbewubsein.

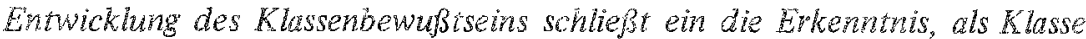
organisient dem Kapital Widerstand leisien zu konnen, schlieft ein die Enkennthis der Nonwendigke der Organistion, des Zusammenwikens dep Arbetrer verachede-

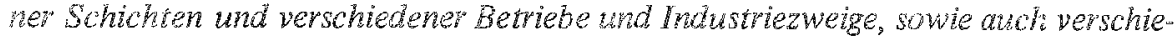
dener potitischer Richtungen, die Auseinandersetzung mit reformistischem BewuBt. sein und reformisischer Politik innerhab der Abeiterklasse sebst. Es schliebt wei. terhin ein de in Organisationsformen umgesetzte Erkentnis, dak die Konkurrenz. mit dem Kapital auf die Dawer nicht gefuht werden kann durch Konkurenz mit anderen Teilen der Lohnabeiterklasse. (Hier wäre wesentich die Stellung der aus. landischen Arbeiter in den westdeutschen Gewerkschaften, ihre mangelnde Vertretung in Betriebsräten aber auch Vertrauenslewen zu diskntieren.)

Anderenseits muß aber klar sein, dah es in dieser Auseinandersetzung um die Demokratisierung, um eine politische Auseinandersetang geht, dio Macht dex Ar. beter as geselschaftich handelnce Kasse entgegen den vebügerichten Foman iher Intevessenwahmehrumg wid inhathicher Interessenformulieren an entwickem. Tie Veranderang der Grganisation kan nur den Sim haben, den Arbeiten iber. haupt de Moghouket des organisierten Kampies $2 u$ geben, in welchem sie au der einen Seite ihren Untexnehmer nicht mehr als Einzelkapitalisten, sondern als Ted der Kapitalistenklasse, d. h. des Klassengegeners, der hekämph werden muß und bekampft werden kamn, erfahren - auf der anderen Seite die Organisiorung selbst als Mitel und notwendige Voraussetzurg zur Umwalzung de bestehenten Verhalt. nisse begreifen, und damit auch die Grenzen ihrer gegenwirtgen Organisationsfor. men.

Herbei handelt es sich wesentich auch un die uber die gewertschaftichen Kampte selbst vermittelte Auseinandersetzung nit der SPD als einer Parei, welche whe Interessen der Arbeiter nur solange zu vertewn gewillt ist, als die Arbeiter inte Interessen als mit den bestehenden kapitalistischen Verhälnissen mehr oder weniger bruchlos vereinbare formulieren, andernfalls jedoch bereit ist, den shathchen Machtapparat auch gegen die Arbeiter einzusetzen.

Herin ist eingeschlossen, dab die Entwicklung der Vertrauensteutekopper als Karnpfanige gewerkschafliche Basisorgane mit wem hartesten Widerstanc von Sein ten der SPL und auch der Gewerkschaftsfuhrung zu rechnen hat, (vgl. die neuen Richtlinien zur Vertrauensleutearbeit in der IG-Metall) und daß sie sich mit dem Vorwurf kommunistischer Wühlarbeit oder linken Chaotentums früher oder später konfrontiert werden sieht.

Wird nicht gesehen, daß die Entwicklung der Gewerkschaft als Klassenkampforganisation einhergehen muß mit der politischen Auseinandersetzung mit dem Kefomismus, so läuf sie Gefanr, die betrieblichen Gewerkschaftskałer spätestens dann in die Resignation zu treiben, wenn das Kapital die Schließung des Betriebes, die Verlagerung de Produktion ins Ausland die Einschränkung der Produktion androht; wenn die SPD-Regierung glaubwurdig Lohnsteigening und Arbeitslosigkeit als Alternativen propagier, wem die SPD verkindet, nur eine Stilhaltepolitik der Arbeiter werde den nächsten Wahlsieg garantieren. 
Wird der Kampf um die Demokratisierung der Gewerkschaften ernsthaft gefüht, so muls sich früher oder später die Erkenntnis entwickeln, daß das Kapitalverhäitnis die entscheidende Schranke gegen eine Sicherung der Lebensbedingungen der Arbeiter darstellt, und nicht die mehr oder weniger demokratische Organisationsform, die bessere oder schlechtere sozialdemokratische Politik. Diese Erkenntnis kann allerdings massenhaft nur dann gewonnen werden, wenn die Organisation selbst in der Lage ist, die Klassenkämpfe auszutragen. Auch insofern ist der Kampf innerhalb der Gewerkschaft zu fihren.

Das Ausmaß der Spontaneität der Kämpfe und der Kampfbereitschaft sowie die Härte des Kassenkampfs von oben stellte traditionelle Formen der Vertreterpolitik infrage (vgl. z. B. das Problem bei Hoesch). Wo dann, wie bei Ford/Köln, aus der Handlungsfähigkeit der betrieblichen Vertrauensleute die Bildung einer selbständigen Streikleitung resultierte, wird auch von linken Vertrauensleuten das Verhältnis zu dieser als Konkurrenzverhältnis begriffen. Linke Gewerkschafter nehmen sich aber damit die Möglichkeit, Einfluß auf die Politik der Streikleitung zu gewinnen und sind somit auch nicht in der Lage, schwere Fehler derselben zu verhindern. Vergleicht man die Situation 1973 mit den Septemberstreiks, so zeigt sich, daß zwar die Gewerkschaftsinke unter der Bedingung, daß die IG-Metall sich von unten unter Druck setzen läßt, in der Lage ist, eine organisierende Kraft darzustellen und den Willen der Arbeiter in Handlungen der Gewerkschaftsorganisation zu transformieren. Spitzt sich demgegenüber die Distanzierung der Gewerkschaftsführung von den selbständigen Kämpfen der Arbeiter zu, so finden sich die linken Gewerkschaftskader zunächst gerade aufgrund ihrer richtigen Erkenntnis, daß die Gewerkschaft notwendig ist, um den Klassenkampf gegen das Kapital zu führen, in einer Situation, wo Handlungsperspektiven verbaut erscheinen. Gerade weil sich die Gewerkschaftsfuhrung weigert, die Bewegung aufzunehmen, muß sich die Kritik der Arbeiter an der Gewerkschaftspolitik verstärken, was wieder auch bewußte Gewerkschafter vor das Problem stellt, sich entweder aus den Kämpfen herauszuhaiten und damit das Vertraten der Arbeite: zu verlieren, oder aber nur sehr vorsichtig zu agieren oder bei voller Identifizierung mit dem Streik sich offen gegen die Politik der ${ }^{G} G$-Netall zu stellen. Andererseits wird gerade eine solche offene Unterstützung von den Arbeitem erwartet. So resultieren Niederlagen in Einzelbetrieben häufig auch in spontaner Enttäuschung über das Handeln der betrieblichen Gremien, von denen allzu selbstverständlich angenommen wurde, daß sie sich fraglos als Instrument der Karopforganisation den Arbeitern zur Verfügung stellen.

Die Handlungsschranken, denen die betrieblichen Gewerkschafter in ihrer Funktion gegenwärtig ausgesetzt sind, können nicht durch moralischen Appell überwunden werden. Sie zeigen andererseits, daß es eine zu eingeschränkte Perspek tive đer Kämpfe wäre, die Strategie der klassenbewußten Arbeiter und Gewerkschaftskader einzig und allein auf eine Stärkung der betrieblichen Gremien innerhalb der Organisation und ihrer Funktionen auszurichten. Gerade der Widerstand gegen solche Bestrebungen in der IG-Metall macht nur allzu deutlich, daß eine solche Stärkung erst Resultat von Klassenkämpfen sein kann, über welche die Gewerkschaftsfiihrung selbst zur Einschränkung ihrer Disziplinierungspolitik gegenibber linken Gewerkschaftskadem gezwungen wird. 
Vielmehr müssen sich die Arbeiter über den gegenwärtigen Charakter ihrer Organisation sowie über den Stand ihrer Kämpfe mit dem Kapital und dessen Charakter und Strategie klar werden, damit über den eingeschränkten Handlungsspielraum auch der klassenbewußtesten Träger von Vertretungsfunktionen und aus dieser Erkenntnis heraus vorläufige Organisationszusammenhänge innerhalb der $\mathrm{Be}$ triebe und über diese hinaus herstellen, die sich nicht allein auf die Arbeit innerhalb der existierenden Gewerkschaftsorgane beschränken. Dies gilt umso mehr, als viele traditionelle betriebliche Gewerkschaftsorgane und Betriebsräte so beschaffen sind, daß eine alleinige Ausrichtung der Politik auf diese Gremien eine entscheidende Einschränkung tatsächlicher Handlungsmöglichkeit bedeuten würde.

Mit der Skizzierung der gegenwärtigen Handlungsschranken der betrieblichen klassenbewußten Gewerkschaftskader und der vorne ausgeführten allgemeinen Feststellung, daß sozialistische Gewerkschaftsarbeit darauf ausgerichtet sein muß, der Entwicklung des Klassenkampfes in der Gewerkschaft eine Bewegungsform zu schaffen, die Entwicklung des Klassenwiderstandes vermittelt über die Gewerkschaften zu organisieren und so die Gewerkschaften zu Organisationen der bewußten Einheit der Arbeiterklasse zu entwickeln, ist gewissermaßen das Spannungsfeld zwischen Aufgabenstellung und Problemen aktueller sozialistischer Gewerkschaftspolitik abgesteckt. Damit sind u. a. die Fragen aufgeworfen nach den konkreten Formen sozialistischer Gewerkschaftsarbeit und dem Niveau der gegenwärtigen Klassenkämpfe entsprechenden politischen-organisatorischen Zwischenformen, die eine Herausbildung und Konsolidierung von in den Betrieben verankerten sozialistischen Kadern im Zusammenhang mit der Schaffung überbetrieblicher Organisationszusam. menhänge ermöglichen.

Diese hier aufgeworfenen Fragestellungen einer sozialistischen Gewerkschaftsarbeit können von uns hier nicht beantwortet werden. Wir konnten mit diesen Thesen nur den Rahmen, die Bedingungen sozialistischer Gewerkschaftsarbeit als Voraussetzung für einen kollektiven Prozeß $\$$ der solidarischen theoretischen und politischen Auseinandersetzung zur Klärung dieser Fragen skizzieren. In weiteren Diskussions- und Arbeitsschritten wäre daher anzusetzen bei einer Einschätzung der bereits in der Arbeiterklasse entwickelten politischen Potenzen und der existierenden sozialistischen und kommunistischen Gruppen. Eine Kritik an den arbeitenden Gruppen müßte sich dabei nicht an einer Ideologiekritik fixieren, sondern danach fragen, wieweit diese Gruppen in der Lage sind, an den realen Bewegungen anzuknüpfen und diese auf eine sozialistische Perspektive hin zu orientieren. Daß eine solche Orientierung weder durch die bloße Entgegenstellung von Modellen besserer gewerkschaftlicher Politik noch durch die bloße Propagienung des Sozialismus geleistet werden kann, glauben wir in unseren Thesen gezeigt zu haben.

(Januar 1974) 